\title{
Safety, tolerability, pharmacokinetics, and pharmacodynamics of PF-06650833, a selective interleukin-1 receptor-associated kinase 4 (IRAK4) inhibitor, in single and multiple ascending dose randomized phase 1 studies in healthy subjects
}

Spencer I. Danto* ${ }^{*}$, Negin Shojaee, Ravi Shankar P. Singh, Cheryl Li, Steven A. Gilbert, Zorayr Manukyan and lain Kilty

\begin{abstract}
Background: PF-06650833 is a potent, selective inhibitor of interleukin-1 receptor-associated kinase 4 (IRAK4). Two randomized, double-blind, sponsor-open phase 1 studies evaluated the safety, pharmacokinetics, and pharmacodynamics of single (SAD) and multiple ascending doses (MAD) of PF-06650833 immediate-release (IR) and modified-release (MR) oral formulations in healthy adult subjects.

Methods: Study 1 (NCT02224651) was a 96-day, placebo-substitution, SAD study of once-daily (QD) oral PF-06650833 IR 1 to $6000 \mathrm{mg}$ and MR 30 to $300 \mathrm{mg}$ in fasted and fed states. Study 2 (NCT02485769) was a 14-day, placebo-controlled, MAD study of PF-06650833 IR 25 to $750 \mathrm{mg}$ twice daily, IR $1000 \mathrm{mg}$ four times per day, IR $330 \mathrm{mg}$ three times per day, and MR $300 \mathrm{mg}$ QD.

Results: PF-06650833 was generally well tolerated, with no dose-limiting treatment-emergent adverse events (TEAEs) identified in either study. TEAEs were generally mild in severity, with headache, gastrointestinal disorders, and acne most commonly reported. No serious AEs or deaths were reported. A maximum tolerated dose was not established in either study. In the SAD study, food intake delayed absorption of IR $30 \mathrm{mg}$ and increased total exposure by 33\%. Delayed absorption was achieved with the MR formulation ( $T_{\max }$ of $1 \mathrm{~h}$ versus $8 \mathrm{~h}$ for IR $100 \mathrm{mg}$ and MR $100 \mathrm{mg}$ formulations, respectively). Food had no effect on total exposure for MR $30 \mathrm{mg}$, but reduced half-life 1.8-fold and increased $C_{\max }$ by $62 \%$. In the MAD study, accumulation ranged from 0.9-fold to 1.4-fold for $A \cup C_{\text {tau }}$ and 0.9 -fold to 1.3 -fold for $C_{\max }$. Less than $1 \%$ of the dose was recovered unchanged in urine for all dose groups, with renal clearance ranging from 14 to $23 \mathrm{~mL} / \mathrm{min}$ for $\mathrm{IR}<750 \mathrm{mg}$ and MR $300 \mathrm{mg}$. There was a sustained decrease in serum high-sensitivity C-reactive protein for IR $\geq 250 \mathrm{mg}$ and MR $300 \mathrm{mg}$. Based on the cholesterol/ hydroxycholesterol ratio, no apparent CYP3A induction or inhibition was observed.

(Continued on next page)
\end{abstract}

\footnotetext{
* Correspondence: spencer.i.danto@pfizer.com

Cheryl Li, Zorayr Manukyan, and lain Kilty were Pfizer employees at the time of the study.

Immunology and Inflammation Research Unit, Pfizer Worldwide Research \& Development, Cambridge, MA 02139, USA
}

(c) The Author(s). 2019 Open Access This article is distributed under the terms of the Creative Commons Attribution 4.0 International License (http://creativecommons.org/licenses/by/4.0/), which permits unrestricted use, distribution, and reproduction in any medium, provided you give appropriate credit to the original author(s) and the source, provide a link to the Creative Commons license, and indicate if changes were made. The Creative Commons Public Domain Dedication waiver (http://creativecommons.org/publicdomain/zero/1.0/) applies to the data made available in this article, unless otherwise stated. 
(Continued from previous page)

Conclusions: PF-06650833, the first IRAK4 inhibitor to enter clinical development, has a favorable safety and pharmacokinetic profile and has shown evidence of pharmacological effect. The data support continued evaluation in human clinical trials for the treatment of rheumatic and autoimmune diseases.

Trial registration: Clinicaltrials.gov, NCT02224651, registered 25 August 2014; NCT02485769, registered 30 June 2015

Keywords: IRAK4, Pharmacokinetic, Pharmacodynamic

\section{Background}

Autoimmune diseases such as rheumatoid arthritis (RA) and systemic lupus erythematosus (SLE) represent a continuing burden worldwide $[1,2]$. In the Global Burden of Disease 2010 study, RA was ranked as the 42nd highest contributor to global disability, and other musculoskeletal disorders, including SLE, were ranked among the top 10 contributors [1, 2]. While the current estimated global prevalence is $0.24 \%$ for RA [1], and up to $0.24 \%$ for SLE $[3,4]$, it is expected that the number of people affected by these diseases will rise with aging populations and declining mortality rates $[1,2]$.

The primary goal of treating-to-target in autoimmune diseases is to achieve clinical remission or sustained low disease activity when remission cannot be achieved (such as in patients with long disease duration) [5, 6]. However, remission is often an unrealized target in clinical practice for patients with RA and SLE, with remission rates as low as $6.5-8.6 \%$ and $1.7 \%$ reported, respectively $[3,7,8]$. In addition, despite treatment, patients with RA and SLE often experience residual pain, fatigue, and impaired physical functioning [9]. Clearly, there remains an unmet medical need for therapies that advance the goal of achieving remission in all patients.

Interleukin (IL)-1 receptor-associated kinase 4 (IRAK4) is an essential signal transducer downstream of the IL-1 family receptors (IL-1R, IL-18R, and IL-33R) and the Tolllike receptors (TLRs) $[10,11]$. TLRs detect bacterial and viral pathogens and may be activated by immune complexes, such as anti-citrullinated protein/peptide autoantibodies in RA $[12,13]$ and nucleic acid immune complexes in SLE [14, 15].

PF-06650833 is a selective, highly potent, small molecule, reversible inhibitor of IRAK4 [16]. Prior in vitro and in vivo studies have reported the inhibition of TLRinduced inflammation by small molecular inhibitors of IRAK4, including PF-06650833 [16-18]. Inhibition of IRAK4 blocks the production of inflammatory cytokines in human monocytes, including type I interferons, IL-1, IL-6, IL-12, and tumor necrosis factor, which are key drivers of autoimmune and inflammatory diseases in response to immune complex activation $[17,19,20]$. Therefore, IRAK4 is an attractive therapeutic target for diseases associated with dysregulated inflammation, such as RA, SLE, spondyloarthritis, and psoriatic arthritis.
Here, we report results from two phase 1 clinical studies in healthy subjects that evaluated the safety, tolerability, pharmacokinetics (PK), and pharmacodynamics (PD) of single (SAD) and multiple ascending doses (MAD) of PF-06650833 administered orally as immediate-release (IR) and modified-release (MR) formulations. These studies also provide preliminary evaluations of the effects of food on exposure. To our knowledge, PF-06650833 is the first IRAK4 inhibitor to enter clinical development and report safety, tolerability, PK, and PD results, which support continued exploration of IRAK4 inhibition in the treatment of rheumatic and other autoimmune diseases.

\section{Methods \\ Study objectives}

The primary objective of study 1 was to determine the safety and tolerability of SAD of orally administered IR and MR formulations of PF-06650833 in healthy adult subjects. Secondary objectives were to evaluate the plasma PK profiles of these formulations and to provide a preliminary assessment of the effect of food on the plasma PK profile of PF-06650833 (after fasting or a high-fat meal).

The primary objective of study 2 was to determine the safety and tolerability of MAD of orally administered IR and MR formulations of PF-06650833 after a standard meal in healthy adult subjects. The secondary objective was to evaluate the plasma and urine PK profiles of PF-06650833 after repeat dosing. Exploratory objectives were to assess the effects of PF-06650833 on exploratory biomarkers of PD activity, including high-sensitivity C-reactive protein (hsCRP), and to evaluate cholesterol/ hydroxycholesterol ratios as an endogenous marker for cytochrome P450 3A (CYP3A) induction or inhibition [21].

\section{Study design and treatment \\ Study 1: SAD}

Study 1 (B7921001; NCT02224651) was a 96-day, phase 1, within-cohort, randomized, double-blind, sponsor-open, placebo-substitution, five-period crossover, SAD study in healthy adult subjects (Fig. 1a). Subjects were sequentially enrolled into four cohorts of ten subjects each. Within each cohort, the subjects were randomized into a maximum of five periods. Within each period, eight subjects and two subjects were randomized to receive PF-06650833 and placebo, respectively. In this placebo-substitution design, all 

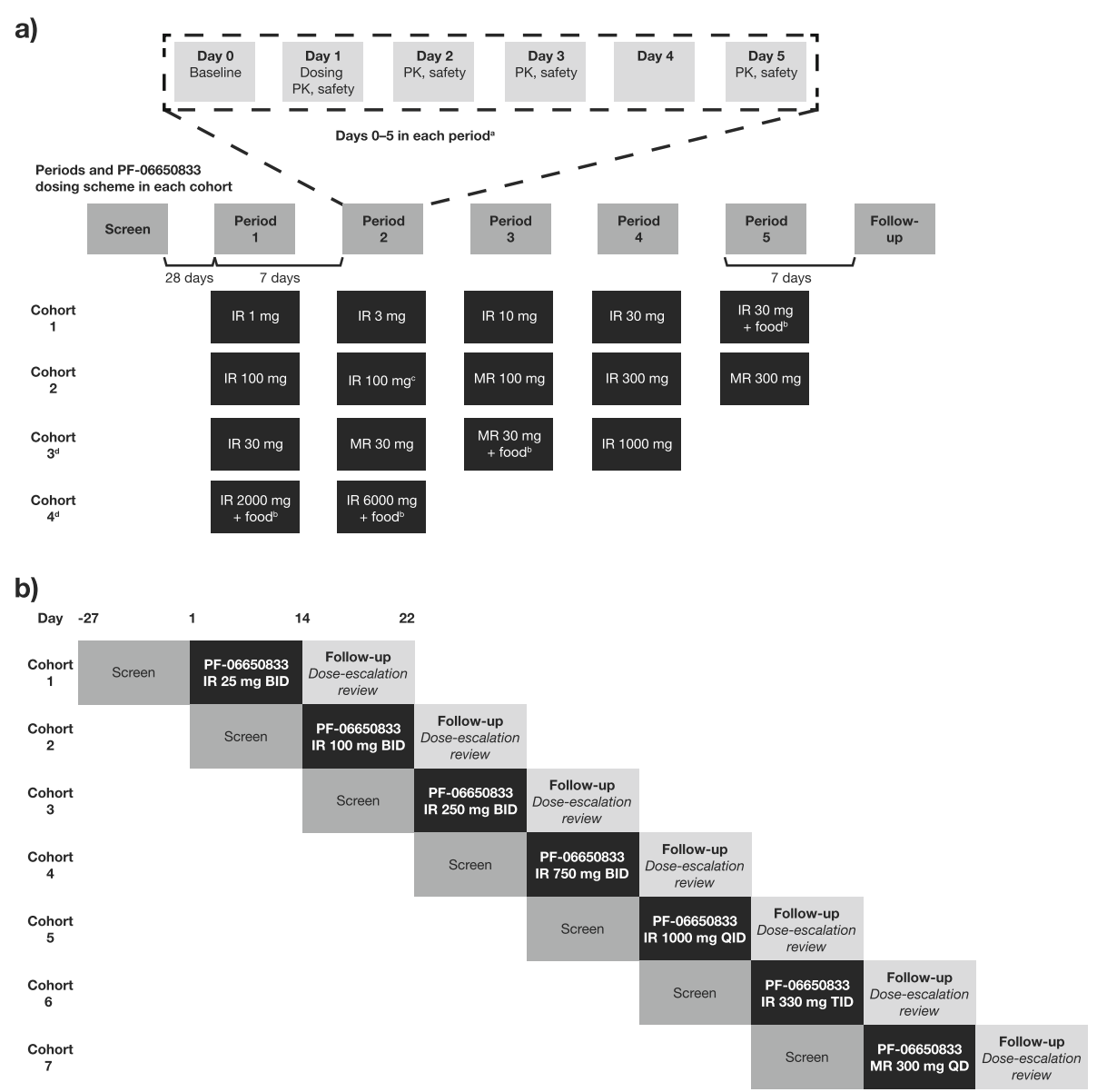

Fig. 1 Design and PF-06650833 final dosing scheme in a study 1 (SAD) and $\mathbf{b}$ study 2 (MAD). ${ }^{\text {aPK }}$ and PD sampling time was up to $96 \mathrm{~h}$ for cohorts 1 and 2. Subjects in cohorts 3 and 4 were followed up to day 21 of the final period to better characterize the terminal phase, given the potentially long elimination half-life based on emerging data. ${ }^{b}$ Dose administered after consumption of a high-fat breakfast meal. ${ }^{\mathrm{C} A l t e r n a t e} \mathrm{IR}$ formulation. ${ }^{\mathrm{d} C o h o r t} 3$ consisted of only four periods, and cohort 4 consisted of only two periods that were separated by 14 days, in order to maintain the overall predicted exposure in an individual subject to $\leq 28$ days. In study 1, within each period, 8 subjects were randomized to receive PF-06650833 and 2 subjects were randomized to receive placebo. All subjects within a cohort received one or more doses of PF-06650833 and/or placebo. Doses were escalated sequentially within each period, based on evaluation of $\geq 48 \mathrm{~h}$ of safety and tolerability for all subjects and $\geq 8 \mathrm{~h}$ of PK data for at least 6 subjects receiving PF-06650833 and 1 subject receiving placebo. All doses were administered orally under fasting conditions (overnight fast of $\geq 10 \mathrm{~h}$ ) unless otherwise indicated. In study 2, within each cohort, eight subjects were planned to receive PF-06650833 and 2 subjects were planned to receive placebo. All doses were administered orally under standard (not high-fat) meal, fed conditions. QD doses were $24 \mathrm{~h}$ apart, BID doses were $12 \mathrm{~h}$ apart, TID doses were $8 \mathrm{~h}$ apart, and QID doses were $6 \mathrm{~h}$ apart. When dosing in the fed condition, the morning and evening doses were administered within 5 min of completing the standard meal. BID twice daily; $I R$ immediate-release: MAD multiple ascending doses; MR modified-release; PK pharmacokinetics; QD once daily; QID four times per day; SAD single ascending doses; TID three times per day

subjects within a cohort received one or more doses of PF-06650833 and/or placebo. Single oral doses of PF-06650833 IR formulations from 1 to $6000 \mathrm{mg}$, and MR formulations from 30 to $300 \mathrm{mg}$, were administered in fasted (overnight fast of $\geq 10 \mathrm{~h}$ ) and/or fed (high-fat breakfast meal) states. Doses were escalated sequentially by period within each cohort (see Fig. 1a for final dosing scheme), based upon the evaluation of $\geq 48 \mathrm{~h}$ of safety and tolerability for all subjects and $\geq 8 \mathrm{~h}$ of $\mathrm{PK}$ data for at least six subjects receiving PF-06650833 and one subject receiving placebo. Dose escalation was to cease when either the limits of safety and/or tolerability were reached, the projected exposure at the subsequent dose exceeded the toxicokinetic limit (TK) established based on the no observable adverse effect level (NOAEL) in relevant animal studies, or a plateau in exposure was reached.

The effects of food on the plasma PK profile of the IR and MR formulations were explored in cohorts 1 and 3, respectively, by administering $30 \mathrm{mg}$ doses of PF-06650833 in a fasted state and after a high-fat meal. A 1000-mg dose of the IR formulation was also tested in cohort 3 in an attempt to identify a maximum tolerated dose (MTD). 
Since TK limits were not reached with the IR formulation at doses up to $1000 \mathrm{mg}$, the IR doses were escalated to 2000 and $6000 \mathrm{mg}$ with a high-fat meal in cohort 4 (Fig. 1a).

\section{Study 2: $M A D$}

Study 2 (B7921002; NCT02485769) was a 14-day, phase 1, randomized, double-blind, sponsor-open, placebo-controlled, sequential group, MAD study in healthy adult subjects (Fig. 1b).

Subjects were enrolled sequentially into seven cohorts. Within each cohort, eight subjects and two subjects were randomized to receive PF-06650833 and placebo, respectively. Doses for all cohorts were administered after a standard (not high-fat) meal. Multiple dosing regimens (once daily [QD] $24 \mathrm{~h}$ apart, twice daily [BID] $12 \mathrm{~h}$ apart, three times per day [TID] $8 \mathrm{~h}$ apart, and four times per day [QID] $6 \mathrm{~h}$ apart) were used to provide required total daily doses. In the final dosing scheme, multiple oral doses of PF-06650833 IR suspension formulations at 25, 100, 250, and $750 \mathrm{mg}$ BID and $1000 \mathrm{mg}$ QID were administered in cohorts 1-5. PF-06650833 IR $330 \mathrm{mg}$ TID (cohort 6) and an MR tablet at a dose of $300 \mathrm{mg}$ QD (cohort 7) were also evaluated (see Fig. 1b for final dosing scheme).

Dose escalation (cohorts 1-5) or dose selection (cohorts 6-8) was based upon the evaluation of $\geq 7$ days of safety and tolerability for all subjects and $\geq 12 \mathrm{~h}$ of PK data for at least six subjects receiving PF-06650833. To establish an MTD, dose escalation was to cease when the limit of tolerability was achieved.

\section{Randomization}

In both studies, subjects were assigned to dose groups according to a pre-defined randomization schedule (see Additional file 1: Supplemental Methods). In both studies, study sponsor treatment administrators were blinded to the treatment allocation, and additional study sponsor personnel (for example, analytical staff, medical monitors, clinicians, statisticians, and pharmacokineticists) were unblinded to subject treatment allocation to permit real-time interpretation of the safety and PK data and to provide information necessary for dose escalation decisions.

\section{Subjects}

In both studies, healthy male and female (of nonchildbearing potential) subjects aged $18-55$ years were eligible to participate. Subjects were to abstain from all medications (prescription, non-prescription, and/or dietary supplements) within 7 days or five half-lives (whichever was longer) prior to the first dose of PF-06650833 or placebo, except medications for the treatment of adverse events (AEs). Where possible, treatments for AEs were to avoid the use of moderate/strong inhibitors or inducers of CYP3A4. Herbal supplements and hormone replacement therapies must have been discontinued 28 days prior to the first dose of PF-06650833 or placebo. As an exception, acetaminophen/paracetamol was permitted at doses of $\leq 1 \mathrm{~g} /$ day. Exclusion criteria also included any clinically significant comorbid disease, screening supine blood pressure $\leq 100$ or $\geq 140 \mathrm{mmHg}$ (systolic) or $\leq 50$ or $\geq 90 \mathrm{mmHg}$ (diastolic), screening pulse or heart rate $>100$ beats $/ \mathrm{min}$, or active or latent infection (including tuberculosis, HIV, and hepatitis viruses).

\section{Assessments}

For both studies, samples of blood (and urine in study 2) were taken for evaluation of PK/PD parameters (see Additional file 1: Supplemental Methods). PK samples were obtained at the nominal time relative to dosing $( \pm 10 \%)$. Plasma and urine samples were analyzed using validated, sensitive, and specific liquid chromatography tandem mass spectrometric methods (at Pfizer Inc., Groton, CT, USA, for study 1 and at Worldwide Pharmacokinetics, Dynamics and Metabolism, Cambridge, MA, USA, for study 2). The lower limit of quantification for PF-06650833 in plasma was $0.0500 \mathrm{ng} / \mathrm{mL}$. The lower limit of quantification for PF-06650833 in urine was $1.00 \mathrm{ng} / \mathrm{mL}$. Serum samples were also analyzed for hsCRP, and plasma samples were analyzed for $4 \beta$-hydroxycholesterol and cholesterol.

Safety assessments included incidence and severity of treatment-emergent AEs (TEAEs) and discontinuation due to TEAEs, incidence of treatment-emergent clinical laboratory abnormalities, and proportion of subjects meeting with pre-defined criteria for potential clinical concern in vital signs and electrocardiogram (ECG) parameters.

\section{PK and safety analyses}

Sample sizes were based on clinical considerations (estimated number required to provide safety, tolerability, and pharmacological information and to minimize exposure to healthy subjects at each dose level) rather than statistical considerations. For study 1, the required total sample size was approximately 40 subjects (10 per cohort); for study 2 , the required total sample size was approximately 80 subjects (10 per cohort). In study 1 , a sample size of 6 subjects was sufficient to provide $>90 \%$ power to detect a food effect-related 2-fold increase of maximum observed concentration $\left(C_{\max }\right)$ or area under the concentration-time profile curve (AUC) and $80 \%$ power to detect a 1.6-fold increase in both PK parameters for all doses except $1000 \mathrm{mg}$, assuming that the predicted within-subject PK variability would not change with food intake. 
The safety analysis set was defined as all subjects who received at least one dose of study treatment, and data were summarized descriptively. The PK concentration analysis set was defined as all enrolled, treated subjects who had at least one concentration in at least one treatment period. The PK parameter analysis set was defined as all enrolled, treated subjects who had at least one of the PK parameters of interest in at least one treatment period. The PD analysis set was defined as all enrolled subjects who received at least one dose of PF-06650833 and had at least one PD parameter. PK/PD data were summarized descriptively.

PK parameters were calculated using non-compartmental analysis of concentration-time data. For study 1 only, data from cohort 1 (period 4 [IR $30 \mathrm{mg}$ ] versus period 5 [IR $30 \mathrm{mg}+$ food]) and cohort 3 (period 2 [MR $30 \mathrm{mg}$ ] versus period 3 [MR $30 \mathrm{mg}$ + food]) were used to estimate the effect of food intake. $C_{\max }$ and AUC were calculated for each subject and treatment, with and without food, after which a within-subject difference could be found between fed (high-fat meal) and fasted doses. Analysis of covariance was used to model these within-subject differences and to calculate 95\% confidence intervals (CIs) for the differences for each dose (IR $30 \mathrm{mg}$ and MR $30 \mathrm{mg}$ ). For study 2 only, the amounts of PF-06650833 in urine and renal clearance were listed and summarized descriptively. As part of the routine safety laboratory monitoring, the presence of any atypical crystals in urine specimens was semiquantitatively assessed microscopically by typical histopathologic methods and scored as numbers of crystals per high power field (hpf); higher abundance (moderate or many) was defined as $\geq 15 / \mathrm{hpf}$. No formal interim analyses were conducted.

\section{Ethical considerations and consent}

These studies were conducted in accordance with the International Ethical Guidelines for Biomedical Research Involving Human Subjects, the Declaration of Helsinki, and the Good Clinical Practice Guidelines, along with applicable local regulatory requirements and laws. The study protocols were approved by the Institutional Review Boards and/or Independent Ethics Committee at each study center. All subjects provided written, informed consent.

\section{Results}

\section{Subjects}

In study 1 , a total of 40 subjects were randomized and received at least 1 dose of PF-06650833, and 31 subjects received placebo. In terms of gender and ethnicity, all subjects were male, with $52.5 \%$ black, $17.5 \%$ white, $5.0 \%$ Asian, and $25.0 \%$ of another race. Mean (standard deviation (SD)) age was 38.5 (8.8) years, and all subjects were similar in regard to weight (mean [SD] 83.7 [11.8] kg), body mass index (BMI; $\left.26.4[3.3] \mathrm{kg} / \mathrm{m}^{2}\right)$, and height $(178.1[6.5] \mathrm{cm})$. All treated subjects $(N=40)$ were evaluated for safety and PK.

In study 2, a total of 71 subjects were randomized; 56 subjects received PF-06650833 (IR or MR) at doses ranging from $25 \mathrm{mg}$ BID to $1000 \mathrm{mg}$ QID, and 15 subjects received placebo. In terms of gender and ethnicity, the majority of the subjects were male (97.2\%), with $45.1 \%$ black, $22.5 \%$ white, $1.4 \%$ Asian, and $31.0 \%$ of another race. Mean (SD) age was 35.1 (8.2) years, and all subjects were similar in regard to weight (mean [SD] 82.0 [9.9] kg), BMI (26.2 [2.7] $\left.\mathrm{kg} / \mathrm{m}^{2}\right)$, and height $(177.0[7.0] \mathrm{cm})$. All treated subjects $(N=71)$ were evaluated for safety and PK.

\section{Safety \\ Discontinuations}

In study 1 , one subject was discontinued and withdrawn per investigator request on the first day of administration due to pre-existing benign ethnic neutropenia after receiving a single dose of PF-06650833 IR $10 \mathrm{mg}$, since this would have complicated the interpretation of safety data.

In study 2, four subjects were discontinued: one each in the placebo, PF-06650833 IR $750 \mathrm{mg}$ BID, IR $1000 \mathrm{mg}$ QID, and MR $300 \mathrm{mg}$ QD dose groups. The subjects in the placebo and MR $300 \mathrm{mg}$ QD dose groups were no longer willing to participate in the study, and two subjects were discontinued due to treatment-related TEAEs as described below.

One subject in the IR $750 \mathrm{mg}$ BID dose group of study 2 was discontinued on day 8 due to decreased appetite, after a prolonged period (beginning after the first dose of study drug on day 1) of pronounced gastrointestinal complaints and symptoms. The subject experienced mild nausea soon after dosing on day 1 that was exacerbated by food intake, and the subject had frequent episodes of vomiting after meals. The nausea became moderate after several days of dosing and was accompanied by moderate lack of appetite until the subject was discontinued. The TEAE was considered treatment-related, but other etiologies, such as viral gastroenteritis, could not be excluded. No other subject in the same or next higher (1000 mg PF-06650833) dose group demonstrated similar nausea symptoms.

One subject in the IR $1000 \mathrm{mg}$ QID dose group of study 2 was discontinued on day 7 due to neutropenia. The subject's absolute neutrophil count (ANC) declined from $2000 / \mathrm{mm}^{3}$ at screening and $1600 / \mathrm{mm}^{3}$ at the time of randomization to $900 / \mathrm{mm}^{3}$ on day $4,1400 / \mathrm{mm}^{3}$ on day 5 , and $1300 / \mathrm{mm}^{3}$ on day 7 , which met the individual subject discontinuation criterion of ANC $<1500 / \mathrm{mm}^{3}$ on two consecutive scheduled measurements. The TEAE 
was considered treatment-related due to a temporal relationship with initial PF-06650833 dosing; however, further review revealed a history prior to study entry of low ANC in the subject. Although a causal relationship to PF-06650833 cannot be excluded, it is possible that the observed fluctuation in ANC was due to the previously undiagnosed cyclic (benign ethnic) neutropenia.

All nine remaining subjects in cohort 5 (IR $1000 \mathrm{mg}$ QID dose group) were electively discontinued after the second dose on day 9 due to the observation of higher abundance ( $>15 / \mathrm{hpf}$ ) atypical crystals in the urine of four of these subjects on day 7. All subjects were asymptomatic and demonstrated no clinical or laboratory evidence of renal injury. These subjects were followed for safety, underwent early termination visit assessments on day 10 , and were discharged from the study after followup on day 22 .

\section{Adverse events}

In study 1 , more all-causality TEAEs were reported with higher dose levels of IR PF-06650833, but no clear dose relationship was observed at doses $\geq 1000 \mathrm{mg}$ (Table 1). The highest number of TEAEs occurred in subjects who received the IR $100 \mathrm{mg}$ formulation (11 TEAEs in 3 subjects) and in subjects who received placebo (6 TEAEs in 4 subjects). Four TEAEs in 2 subjects were reported with the $300 \mathrm{mg}$ MR formulation, while no TEAEs were reported with the $300 \mathrm{mg}$ IR formulation. A total of 10 treatment-related TEAEs were reported in 4 subjects receiving IR PF-06650833, including 1 reporting acne (IR $30 \mathrm{mg}$; fed state), 2 reporting headache (IR $2000 \mathrm{mg}$ and $6000 \mathrm{mg}$; both fed state), and 1 whose reported TEAEs, numbering 7 overall, included multiple gastrointestinal disorders (IR $100 \mathrm{mg}$; fasted). No treatment-related TEAEs were reported in subjects receiving PF-06650833 MR formulations or placebo.

In study 2, a total of 62 all-causality TEAEs were reported in 35 subjects, with PF-06650833 IR $750 \mathrm{mg}$ BID having the highest number of TEAEs $(n=17)$, followed by IR $1000 \mathrm{mg}$ QID $(n=11)$ and placebo $(n=9)$ (Table 2). No clear dose or regimen relationship was observed with respect to the number of TEAEs. A total of 36 treatmentrelated TEAEs were reported in 20 subjects, with headache, nausea, upper abdominal pain, and acne being the most common.

In both studies, all TEAEs were mild or moderate in severity, and most resolved without intervention. There were no dose reductions and/or temporary discontinuations due to TEAEs, serious AEs, or deaths reported in either study. There were no clinically significant changes in vital signs, ECGs, laboratory data, or dose-limiting TEAEs for either study.

In study 2, the presence of asymptomatic, nonadverse, atypical crystals in the urine was identified in 25 subjects (including 3 subjects receiving placebo). The presence of urine crystals at higher abundance $(\geq 15 /$ hpf) was restricted to PF-06650833 doses $\geq$ IR $750 \mathrm{mg}$ BID and was not persistent. None of the subjects presenting with urine crystals had TEAEs, other abnormal clinical signs or symptoms, or clinical laboratory data (serum creatinine or estimated glomerular filtration rate) suggestive of adverse effects on renal function.

\section{Pharmacokinetics \\ Study 1: SAD}

Median plasma concentration-time profiles of SAD of the PF-06650833 IR and MR oral formulations are presented in Fig. 2. Plasma PK parameters for both formulations are summarized in Table 3.

When administered in the fasted state, plasma concentrations of PF-06650833 increased in a dose-dependent manner with SAD of $\leq 100 \mathrm{mg}$ for both IR and MR formulations and in a less than proportional manner with higher doses; lower $C_{\max }$ values were observed for all comparable doses of MR versus IR formulations as expected. Dose-normalized $C_{\max }$ and AUC from time zero extrapolated to infinity $\left(\mathrm{AUC}_{\text {inf }}\right)$ values for PF-06650833 IR and MR formulations are shown in Additional file 1: Figure S1. Absorption was rapid for the PF-06650833 IR formulation (median time of $C_{\max }\left[T_{\max }\right] 0.5-2.0 \mathrm{~h}$ across the 1-1000 $\mathrm{mg}$ dose range) compared with the more gradual absorption of the MR formulation (median $T_{\max } 4.0-8.0 \mathrm{~h}$ over the $30-300 \mathrm{mg}$ dose range). Half-life was similar for PF-06650833 IR versus MR formulations at comparable nominal doses of $30-100 \mathrm{mg}$ (mean terminal half-life $\left[t_{1 / 2}\right] 10.2-15.0$ and $9.4-11.7 \mathrm{~h}$, respectively) but was longer for MR $300 \mathrm{mg}$ (mean $t_{1 / 2} 38.8 \mathrm{~h}$ ) versus IR $300 \mathrm{mg}$ (mean $t_{1 / 2} 19.9 \mathrm{~h}$ ), for which a longer terminal phase was measured.

Following single oral doses of PF-06650833 IR and MR $30 \mathrm{mg}$ formulations, absorption was delayed in the fed (high-fat meal) versus fasted ( $\geq 10 \mathrm{~h}$ ) state for the IR $30 \mathrm{mg}$ dose (median $T_{\max } 4.0$ versus $0.5 \mathrm{~h}$ ), but was not affected by food for the MR $30 \mathrm{mg}$ dose (median $T_{\max }$ $6.0 \mathrm{~h}$ for both). Half-life was reduced in the fed state for both IR ( $t_{1 / 2} 10.2$ to $\left.4.4 \mathrm{~h}\right)$ and MR ( $t_{1 / 2} 11.7$ to $6.33 \mathrm{~h}$ ) formulations.

Co-administration of IR $30 \mathrm{mg}$ with a high-fat meal increased total exposure by $33 \%\left(\mathrm{AUC}_{\text {inf }}[\mathrm{ng} \cdot \mathrm{h} / \mathrm{mL}] 211.3\right.$ versus 316.1 for fasted and fed conditions, respectively; fasted/fed ratio $66.8 \%$ [95\% CI 57.49, 77.71]), but did not have an effect on $C_{\max }(57.62$ versus $54.21 \mathrm{ng} / \mathrm{mL}$ for fasted and fed conditions, respectively; fasted/fed ratio $106.30 \%$ [95\% CI 83.69, 135.03]). Conversely, $C_{\max }$ increased by $62 \%$ in the fed state for MR $30 \mathrm{mg}\left(C_{\max } 14.97\right.$ versus $39.34 \mathrm{ng} / \mathrm{mL}$ for fasted and fed conditions, respectively; fasted/fed ratio $38.05 \%$ [ $95 \%$ CI $29.45,49.16]$ ), while total exposure remained unaffected $\left(\mathrm{AUC}_{\mathrm{inf}} 260.9\right.$ versus 
Table 1 Study 1 (SAD) TEAEs. All causalities (treatment-related)

\begin{tabular}{|c|c|c|c|c|c|c|c|c|c|c|c|c|c|c|c|c|}
\hline & \multirow[t]{2}{*}{ Placebo $^{a}$} & \multicolumn{15}{|c|}{ PF-06650833 dose group } \\
\hline & & $\begin{array}{l}\mathrm{IR} 1 \\
\mathrm{mg}\end{array}$ & $\begin{array}{l}\mathrm{IR} \\
3 \\
\mathrm{mg} \\
\end{array}$ & $\begin{array}{l}\mathbb{R} \\
10 \\
\mathrm{mg} \\
\end{array}$ & $\begin{array}{l}\mathrm{IR} \\
30 \\
\mathrm{mg} \\
\end{array}$ & $\begin{array}{l}\text { IR } 30 \\
\text { mg } \\
\text { (fed) }\end{array}$ & $\begin{array}{l}\text { IR } \\
100 \\
\mathrm{mg}\end{array}$ & $\begin{array}{l}\text { IR } \\
100 \\
\mathrm{mg}^{\mathrm{b}}\end{array}$ & $\begin{array}{l}\text { IR } \\
300 \\
\mathrm{mg}\end{array}$ & $\begin{array}{l}\text { IR } \\
1000 \\
\mathrm{mg}\end{array}$ & $\begin{array}{l}\text { IR } 2000 \\
\mathrm{mg} \\
\text { (fed) }\end{array}$ & $\begin{array}{l}\text { IR } 6000 \\
\mathrm{mg} \\
\text { (fed) }\end{array}$ & $\begin{array}{l}\mathrm{MR} \\
30 \\
\mathrm{mg}\end{array}$ & $\begin{array}{l}\text { MR } 30 \\
\text { mg } \\
\text { (fed) }\end{array}$ & $\begin{array}{l}\text { MR } \\
100 \\
\mathrm{mg}\end{array}$ & $\begin{array}{l}\mathrm{MR} \\
300 \\
\mathrm{mg}\end{array}$ \\
\hline Subjects evaluable for AEs & 31 & 8 & 8 & 8 & 15 & 8 & 8 & 8 & 8 & 8 & 8 & 8 & 8 & 8 & 8 & 8 \\
\hline Subjects with AEs & $4(0)$ & $1(0)$ & 0 & 0 & 0 & $1(1)$ & $1(0)$ & $2(1)$ & 0 & $2(0)$ & $3(1)$ & $2(1)$ & 0 & 0 & $1(0)$ & $2(0)$ \\
\hline Number of AEs & $6(0)$ & $1(0)$ & 0 & 0 & 0 & $1(1)$ & $1(0)$ & $10(7)$ & 0 & $3(0)$ & $4(1)$ & $2(1)$ & 0 & 0 & $1(0)$ & $4(0)$ \\
\hline \multicolumn{17}{|l|}{$\begin{array}{l}\text { Number of subjects with AEs } \\
\text { by system organ class and } \\
\text { preferred term }\end{array}$} \\
\hline $\begin{array}{l}\text { Ear and labyrinth } \\
\text { disorders }\end{array}$ & $1(0)$ & 0 & 0 & 0 & 0 & 0 & 0 & 0 & 0 & 0 & 0 & 0 & 0 & 0 & 0 & 0 \\
\hline Vertigo & $1(0)$ & 0 & 0 & 0 & 0 & 0 & 0 & 0 & 0 & 0 & 0 & 0 & 0 & 0 & 0 & 0 \\
\hline $\begin{array}{l}\text { Gastrointestinal } \\
\text { disorders }\end{array}$ & $1(0)$ & 0 & 0 & 0 & 0 & 0 & 0 & $1(1)$ & 0 & 0 & $1(0)$ & 0 & 0 & 0 & 0 & $1(0)$ \\
\hline $\begin{array}{l}\text { Abdominal } \\
\text { discomfort }\end{array}$ & 0 & 0 & 0 & 0 & 0 & 0 & 0 & 0 & 0 & 0 & 0 & 0 & 0 & 0 & 0 & $1(0)$ \\
\hline Abdominal distension & 0 & 0 & 0 & 0 & 0 & 0 & 0 & 0 & 0 & 0 & $1(0)$ & 0 & 0 & 0 & 0 & 0 \\
\hline Abdominal pain & 0 & 0 & 0 & 0 & 0 & 0 & 0 & $1(1)$ & 0 & 0 & 0 & 0 & 0 & 0 & 0 & 0 \\
\hline Diarrhea & 0 & 0 & 0 & 0 & 0 & 0 & 0 & $1(1)$ & 0 & 0 & 0 & 0 & 0 & 0 & 0 & $1(0)$ \\
\hline Dry mouth & 0 & 0 & 0 & 0 & 0 & 0 & 0 & $1(1)$ & 0 & 0 & 0 & 0 & 0 & 0 & 0 & 0 \\
\hline Enterocolitis & $1(0)$ & 0 & 0 & 0 & 0 & 0 & 0 & 0 & 0 & 0 & 0 & 0 & 0 & 0 & 0 & 0 \\
\hline Flatulence & 0 & 0 & 0 & 0 & 0 & 0 & 0 & $1(1)$ & 0 & 0 & 0 & 0 & 0 & 0 & 0 & 0 \\
\hline $\begin{array}{l}\text { General disorders and } \\
\text { administration site } \\
\text { conditions }\end{array}$ & $1(0)$ & 0 & 0 & 0 & 0 & 0 & 0 & $1(1)$ & 0 & 0 & 0 & 0 & 0 & 0 & 0 & 0 \\
\hline Fatigue & 0 & 0 & 0 & 0 & 0 & 0 & 0 & $1(1)$ & 0 & 0 & 0 & 0 & 0 & 0 & 0 & 0 \\
\hline Pain & $1(0)$ & 0 & 0 & 0 & 0 & 0 & 0 & 0 & 0 & 0 & 0 & 0 & 0 & 0 & 0 & 0 \\
\hline $\begin{array}{l}\text { Infections and } \\
\text { infestations }\end{array}$ & 0 & $1(0)$ & 0 & 0 & 0 & 0 & 0 & 0 & 0 & 0 & $1(0)$ & 0 & 0 & 0 & 0 & 0 \\
\hline Conjunctivitis & 0 & $1(0)$ & 0 & 0 & 0 & 0 & 0 & 0 & 0 & 0 & 0 & 0 & 0 & 0 & 0 & 0 \\
\hline Folliculitis & 0 & 0 & 0 & 0 & 0 & 0 & 0 & 0 & 0 & 0 & $1(0)$ & 0 & 0 & 0 & 0 & 0 \\
\hline $\begin{array}{l}\text { Upper respiratory } \\
\text { tract infection }\end{array}$ & 0 & 0 & 0 & 0 & 0 & 0 & 0 & 0 & 0 & 0 & $1(0)$ & 0 & 0 & 0 & 0 & 0 \\
\hline $\begin{array}{l}\text { Injury, poisoning, and } \\
\text { procedural } \\
\text { complications }\end{array}$ & 0 & 0 & 0 & 0 & 0 & 0 & 0 & 0 & 0 & $1(0)$ & 0 & 0 & 0 & 0 & 0 & 0 \\
\hline Fall & 0 & 0 & 0 & 0 & 0 & 0 & 0 & 0 & 0 & $1(0)$ & 0 & 0 & 0 & 0 & 0 & 0 \\
\hline $\begin{array}{l}\text { Metabolism and } \\
\text { nutrition disorders }\end{array}$ & 0 & 0 & 0 & 0 & 0 & 0 & 0 & $1(1)$ & 0 & 0 & 0 & 0 & 0 & 0 & 0 & 0 \\
\hline Decreased appetite & 0 & 0 & 0 & 0 & 0 & 0 & 0 & $1(1)$ & 0 & 0 & 0 & 0 & 0 & 0 & 0 & 0 \\
\hline $\begin{array}{l}\text { Musculoskeletal and } \\
\text { connective tissue } \\
\text { disorders }\end{array}$ & $1(0)$ & 0 & 0 & 0 & 0 & 0 & 0 & 0 & 0 & $1(0)$ & 0 & 0 & 0 & 0 & 0 & $1(0)$ \\
\hline Arthralgia & 0 & 0 & 0 & 0 & 0 & 0 & 0 & 0 & 0 & $1(0)$ & 0 & 0 & 0 & 0 & 0 & 0 \\
\hline $\begin{array}{l}\text { Musculoskeletal } \\
\text { stiffness }\end{array}$ & 0 & 0 & 0 & 0 & 0 & 0 & 0 & 0 & 0 & 0 & 0 & 0 & 0 & 0 & 0 & $1(0)$ \\
\hline Neck pain & $1(0)$ & 0 & 0 & 0 & 0 & 0 & 0 & 0 & 0 & 0 & 0 & 0 & 0 & 0 & 0 & 0 \\
\hline $\begin{array}{l}\text { Nervous system } \\
\text { disorders }\end{array}$ & $1(0)$ & 0 & 0 & 0 & 0 & 0 & 0 & $1(1)$ & 0 & $1(0)$ & $1(1)$ & $2(1)$ & 0 & 0 & 0 & 0 \\
\hline Dizziness & 0 & 0 & 0 & 0 & 0 & 0 & 0 & $1(1)$ & 0 & 0 & 0 & $1(0)$ & 0 & 0 & 0 & 0 \\
\hline Headache & $1(0)$ & 0 & 0 & 0 & 0 & 0 & 0 & 0 & 0 & $1(0)$ & $1(1)$ & $1(1)$ & 0 & 0 & 0 & 0 \\
\hline
\end{tabular}


Table 1 Study 1 (SAD) TEAEs. All causalities (treatment-related) (Continued)

\begin{tabular}{|c|c|c|c|c|c|c|c|c|c|c|c|c|c|c|c|c|}
\hline & \multirow[t]{2}{*}{ Placebo $^{a}$} & \multicolumn{15}{|c|}{ PF-06650833 dose group } \\
\hline & & $\begin{array}{l}\text { IR } 1 \\
\text { mg }\end{array}$ & $\begin{array}{l}\text { IR } \\
3 \\
\mathrm{mg}\end{array}$ & $\begin{array}{l}\text { IR } \\
10 \\
\mathrm{mg}\end{array}$ & $\begin{array}{l}\text { IR } \\
30 \\
\mathrm{mg}\end{array}$ & $\begin{array}{l}\text { IR } 30 \\
\text { mg } \\
\text { (fed) }\end{array}$ & $\begin{array}{l}\text { IR } \\
100 \\
\mathrm{mg}\end{array}$ & $\begin{array}{l}\text { IR } \\
100 \\
\mathrm{mg}^{\mathrm{b}}\end{array}$ & $\begin{array}{l}\text { IR } \\
300 \\
\mathrm{mg}\end{array}$ & $\begin{array}{l}\text { IR } \\
1000 \\
\mathrm{mg}\end{array}$ & $\begin{array}{l}\text { IR } 2000 \\
\text { mg } \\
\text { (fed) }\end{array}$ & $\begin{array}{l}\text { IR } 6000 \\
\text { mg } \\
\text { (fed) }\end{array}$ & $\begin{array}{l}\mathrm{MR} \\
30 \\
\mathrm{mg}\end{array}$ & $\begin{array}{l}\text { MR } 30 \\
\text { mg } \\
\text { (fed) }\end{array}$ & $\begin{array}{l}\text { MR } \\
100 \\
\mathrm{mg}\end{array}$ & $\begin{array}{l}\text { MR } \\
300 \\
\mathrm{mg}\end{array}$ \\
\hline Psychiatric disorders & 0 & 0 & 0 & 0 & 0 & 0 & 0 & 0 & 0 & 0 & 0 & 0 & 0 & 0 & $1(0)$ & 0 \\
\hline Anxiety & 0 & 0 & 0 & 0 & 0 & 0 & 0 & 0 & 0 & 0 & 0 & 0 & 0 & 0 & $1(0)$ & 0 \\
\hline $\begin{array}{l}\text { Respiratory, thoracic, } \\
\text { and mediastinal } \\
\text { disorders }\end{array}$ & 0 & 0 & 0 & 0 & 0 & 0 & 0 & $1(0)$ & 0 & 0 & 0 & 0 & 0 & 0 & 0 & 0 \\
\hline Hypopnea & 0 & 0 & 0 & 0 & 0 & 0 & 0 & $1(0)$ & 0 & 0 & 0 & 0 & 0 & 0 & 0 & 0 \\
\hline $\begin{array}{l}\text { Skin and subcutaneous } \\
\text { tissue disorders }\end{array}$ & $1(0)$ & 0 & 0 & 0 & 0 & $1(1)$ & $1(0)$ & $1(0)$ & 0 & 0 & 0 & 0 & 0 & 0 & 0 & $1(0)$ \\
\hline Acne & 0 & 0 & 0 & 0 & 0 & $1(1)$ & 0 & 0 & 0 & 0 & 0 & 0 & 0 & 0 & 0 & 0 \\
\hline Dermatitis contact & $1(0)$ & 0 & 0 & 0 & 0 & 0 & $1(0)$ & 0 & 0 & 0 & 0 & 0 & 0 & 0 & 0 & 0 \\
\hline Erythema & 0 & 0 & 0 & 0 & 0 & 0 & 0 & $1(0)$ & 0 & 0 & 0 & 0 & 0 & 0 & 0 & 0 \\
\hline Scab & 0 & 0 & 0 & 0 & 0 & 0 & 0 & 0 & 0 & 0 & 0 & 0 & 0 & 0 & 0 & $1(0)$ \\
\hline Skin irritation & 0 & 0 & 0 & 0 & 0 & 0 & 0 & $1(0)$ & 0 & 0 & 0 & 0 & 0 & 0 & 0 & 0 \\
\hline
\end{tabular}

All doses were administered orally under fasting conditions (overnight fast of $\geq 10 \mathrm{~h}$ ) unless otherwise indicated. Fed doses were administered after consumption of a high-fat breakfast. Subjects were counted only once per treatment in each row. The table includes all data collected since the first dose of study drug $A E$ adverse event, IR immediate-release, $M R$ modified-release, $S A D$ single ascending doses, TEAE treatment-emergent $A E$

${ }^{a}$ Represents placebo groups (IR placebo, IR fed placebo, MR placebo, and MR fed placebo) in all cohorts

${ }^{\mathrm{b}}$ Alternate IR formulation

$287.1 \mathrm{ng} \mathrm{h} / \mathrm{mL}$ for fasted and fed conditions, respectively; fasted/fed ratio $90.86 \%$ [95\% CI 78.40, 105.29]).

When 2000 and $6000 \mathrm{mg}$ IR doses were administered in the fed state, median $T_{\max }$ was 4.0 and $6.0 \mathrm{~h}$, respectively. Following the attainment of $C_{\max }$, PF-06650833 concentrations demonstrated a multiphasic decline. Mean $t_{1 / 2}$ was $72.1 \mathrm{~h}$ for PF-06650833 IR $6000 \mathrm{mg}$ (and was not able to be determined for IR $2000 \mathrm{mg}$ ). In general, the increase in exposure was less than proportional to the increase in dose for the 2000 and $6000 \mathrm{mg}$ IR formulations compared with the lower dose groups.

\section{Study 2: MAD}

Median plasma concentration-time profiles at steady state on day 14 administration of oral MAD of PF-06650833 IR and MR formulations are presented in Fig. 3. Plasma and urine PK parameters for both formulations on day 1 and day 14 are summarized in Table 4.

The PF-06650833 absorption rate was slightly faster on day 1 following initial oral doses of IR 25 to $1000 \mathrm{mg}$ under fed (standard meal) conditions (median $T_{\max } 2-4 \mathrm{~h}$ ), compared with the more gradual absorption of the MR formulation (median $T_{\max } 4 \mathrm{~h}$ ). On day 14, absorption rates were comparable with day 1 values for PF-06650833 IR (median $T_{\max } 2 \mathrm{~h}$ ) and MR (median $T_{\max } 4 \mathrm{~h}$ ) formulations.

Steady state was reached by day 4 for all PF-06650833 dose groups. Across all dosages, mean oral clearance values ranged from 122.4 to $308.0 \mathrm{~L} / \mathrm{h}$, and mean volume of distribution values ranged from $8064 \mathrm{~L}$ to $13,160 \mathrm{~L}$.
Mean half-life values calculated for IR $750 \mathrm{mg}$ BID, IR $330 \mathrm{mg}$ TID, and MR $300 \mathrm{mg}$ QD dosages ranged from 25.4 to $31.4 \mathrm{~h}$. On day 14 , AUC from time 0 to time tau (AUC $_{\text {tau }}$; where tau is the dosing interval $[6,8,12$, and $24 \mathrm{~h}$ for QID, TID, BID, and QD dosing, respectively]) and $C_{\max }$ increased proportionally for IR 25 to $100 \mathrm{mg}$ BID doses, with less than proportional increases observed at doses $\geq 250 \mathrm{mg}$.

Accumulation ranged from 0.9-fold to 1.4-fold for $\mathrm{AUC}_{\text {tau }}$ and 0.9-fold to 1.3-fold for $C_{\text {max }}$. Less than 1\% of the dose was recovered unchanged in the urine for all dose groups, with renal clearance ranging from 14 to $19 \mathrm{~mL} / \mathrm{min}$ for IR $25 \mathrm{mg}$ BID, IR $330 \mathrm{mg}$ TID, and MR $300 \mathrm{mg}$ QD, and $23 \mathrm{~mL} / \mathrm{min}$ for IR $750 \mathrm{mg}$ BID. Dose-normalized $C_{\max }$ and $\mathrm{AUC}_{\text {tau }}$ following MAD of PF-06650833 IR and MR formulations on day 14 are shown in Additional file 1: Figure S2.

Ratios of $4 \beta$-hydroxycholesterol to cholesterol were comparable $(<20 \%$ mean change) between day $14(4 \mathrm{~h}$ post-dose) and day 1 (pre-dose) across the dose groups for doses up to $750 \mathrm{mg}$ BID, indicating no apparent trend for CYP3A induction or inhibition [21].

\section{Pharmacodynamics}

\section{Study 2: MAD}

Geometric mean serum hsCRP levels ranged from 0.067 to $0.101 \mathrm{mg} / \mathrm{dL}$ across the dose groups at baseline. There was a sustained decrease from baseline in serum hsCRP, which, in general, reached maximal reduction by day 7 , following administration of PF-06650833 IR formulations 
Table 2 Study 2 (MAD) TEAEs. All causalities (treatment-related)

\begin{tabular}{|c|c|c|c|c|c|c|c|c|}
\hline & \multirow[t]{2}{*}{ Placebo $^{a}$} & \multicolumn{7}{|c|}{ PF-06650833 dose group } \\
\hline & & $\begin{array}{l}\text { IR } 25 \mathrm{mg} \\
\mathrm{BID}\end{array}$ & $\begin{array}{l}\text { IR } 100 \mathrm{mg} \\
\mathrm{BID}\end{array}$ & $\begin{array}{l}\text { IR } 250 \mathrm{mg} \\
\mathrm{BID}\end{array}$ & $\begin{array}{l}\text { IR } 750 \mathrm{mg} \\
\mathrm{BID}\end{array}$ & $\begin{array}{l}\text { IR } 1000 \mathrm{mg} \\
\text { QID }\end{array}$ & $\begin{array}{l}\text { IR } 330 \mathrm{mg} \\
\text { TID }\end{array}$ & $\begin{array}{l}\text { MR } 300 \mathrm{mg} \\
\text { QD }\end{array}$ \\
\hline Subjects evaluable for AEs & 15 & 8 & 8 & 8 & 8 & 8 & 8 & 8 \\
\hline Subjects with AEs & $6(2)$ & $3(1)$ & $4(2)$ & $3(2)$ & $5(5)$ & $7(4)$ & $3(2)$ & $4(2)$ \\
\hline Number of AEs & $9(3)$ & $3(1)$ & $5(2)$ & $9(7)$ & $17(13)$ & $11(6)$ & $4(2)$ & $4(2)$ \\
\hline \multicolumn{9}{|l|}{$\begin{array}{l}\text { Number of subjects with AEs by system organ } \\
\text { class and preferred term }\end{array}$} \\
\hline Blood and lymphatic system disorders & 0 & 0 & 0 & 0 & 0 & $1(1)$ & 0 & 0 \\
\hline Neutropenia & 0 & 0 & 0 & 0 & 0 & $1(1)$ & 0 & 0 \\
\hline Ear and labyrinth disorders & 0 & 0 & 0 & 0 & 0 & $1(0)$ & 0 & 0 \\
\hline Hypoacusis & 0 & 0 & 0 & 0 & 0 & $1(0)$ & 0 & 0 \\
\hline Eye disorders & $1(0)$ & 0 & 0 & 0 & 0 & $1(0)$ & 0 & 0 \\
\hline Conjunctival hyperemia & $1(0)$ & 0 & 0 & 0 & 0 & 0 & 0 & 0 \\
\hline Conjunctival irritation & 0 & 0 & 0 & 0 & 0 & $1(0)$ & 0 & 0 \\
\hline Gastrointestinal disorders & $1(0)$ & $1(0)$ & $2(2)$ & $2(2)$ & $1(1)$ & $2(2)$ & 0 & 0 \\
\hline Abdominal discomfort & $1(0)$ & 0 & 0 & 0 & 0 & 0 & 0 & 0 \\
\hline Abdominal pain upper & 0 & 0 & $2(2)$ & 0 & $1(1)$ & 0 & 0 & 0 \\
\hline Diarrhea & 0 & 0 & 0 & 0 & 0 & $1(1)$ & 0 & 0 \\
\hline Feces hard & 0 & $1(0)$ & 0 & 0 & 0 & 0 & 0 & 0 \\
\hline Feces soft & 0 & 0 & 0 & 0 & $1(0)$ & 0 & 0 & 0 \\
\hline Flatulence & 0 & 0 & 0 & 0 & 0 & $1(1)$ & 0 & 0 \\
\hline Gastroesophageal reflux disease & 0 & 0 & 0 & 0 & $1(1)$ & 0 & 0 & 0 \\
\hline Nausea & 0 & 0 & 0 & $2(2)$ & $1(1)$ & 0 & 0 & 0 \\
\hline Vomiting & 0 & 0 & 0 & 0 & $1(1)$ & 0 & 0 & 0 \\
\hline $\begin{array}{l}\text { General disorders and administration site } \\
\text { conditions }\end{array}$ & 0 & 0 & 0 & $1(1)$ & $1(1)$ & $1(1)$ & $1(1)$ & 0 \\
\hline Asthenia & 0 & 0 & 0 & $1(1)$ & 0 & 0 & 0 & 0 \\
\hline Fatigue & 0 & 0 & 0 & 0 & $1(1)$ & 0 & 0 & 0 \\
\hline Feeling abnormal & 0 & 0 & 0 & 0 & 0 & 0 & $1(1)$ & 0 \\
\hline Feeling hot & 0 & 0 & 0 & 0 & 0 & $1(1)$ & 0 & 0 \\
\hline Infections and infestations & $1(1)$ & 0 & $1(0)$ & 0 & $1(1)$ & 0 & 0 & $1(0)$ \\
\hline Folliculitis & 0 & 0 & 0 & 0 & $1(1)$ & 0 & 0 & 0 \\
\hline Hordeolum & 0 & 0 & 0 & 0 & 0 & 0 & 0 & $1(0)$ \\
\hline Upper respiratory tract infection & $1(1)$ & 0 & $1(0)$ & 0 & 0 & 0 & 0 & 0 \\
\hline $\begin{array}{l}\text { Injury, poisoning, and procedural } \\
\text { complications }\end{array}$ & $1(0)$ & 0 & 0 & $1(0)$ & 0 & 0 & 0 & 0 \\
\hline Arthropod bite & $1(0)$ & 0 & 0 & $1(0)$ & 0 & 0 & 0 & 0 \\
\hline Metabolism and nutrition disorders & 0 & 0 & 0 & 0 & $1(1)$ & 0 & 0 & 0 \\
\hline Decreased appetite & 0 & 0 & 0 & 0 & $1(1)$ & 0 & 0 & 0 \\
\hline $\begin{array}{l}\text { Musculoskeletal and connective tissue } \\
\text { disorders }\end{array}$ & 0 & $1(0)$ & $1(0)$ & 0 & $1(0)$ & $1(0)$ & 0 & 0 \\
\hline Back pain & 0 & $1(0)$ & 0 & 0 & 0 & 0 & 0 & 0 \\
\hline Muscle spasms & 0 & 0 & 0 & 0 & $1(0)$ & $1(0)$ & 0 & 0 \\
\hline Neck pain & 0 & 0 & $1(0)$ & 0 & 0 & 0 & 0 & 0 \\
\hline Nervous system disorders & $1(0)$ & $1(1)$ & 0 & $2(2)$ & $4(4)$ & $3(2)$ & 0 & 0 \\
\hline Dizziness & 0 & 0 & 0 & $1(1)$ & 0 & 0 & 0 & 0 \\
\hline
\end{tabular}


Table 2 Study 2 (MAD) TEAEs. All causalities (treatment-related) (Continued)

\begin{tabular}{|c|c|c|c|c|c|c|c|c|}
\hline & \multirow[t]{2}{*}{ Placebo $^{a}$} & \multicolumn{7}{|c|}{ PF-06650833 dose group } \\
\hline & & $\begin{array}{l}\text { IR } 25 \mathrm{mg} \\
\text { BID }\end{array}$ & $\begin{array}{l}\text { IR } 100 \mathrm{mg} \\
\text { BID }\end{array}$ & $\begin{array}{l}\text { IR } 250 \mathrm{mg} \\
\mathrm{BID}\end{array}$ & $\begin{array}{l}\text { IR } 750 \mathrm{mg} \\
\text { BID }\end{array}$ & $\begin{array}{l}\text { IR } 1000 \mathrm{mg} \\
\text { QID }\end{array}$ & $\begin{array}{l}\text { IR } 330 \mathrm{mg} \\
\text { TID }\end{array}$ & $\begin{array}{l}\text { MR } 300 \mathrm{mg} \\
\mathrm{QD}\end{array}$ \\
\hline Headache & $1(0)$ & $1(1)$ & 0 & $1(1)$ & $4(4)$ & $2(2)$ & 0 & 0 \\
\hline Presyncope & 0 & 0 & 0 & 0 & 0 & $1(0)$ & 0 & 0 \\
\hline Somnolence & 0 & 0 & 0 & $1(1)$ & 0 & 0 & 0 & 0 \\
\hline Psychiatric disorders & 0 & 0 & $1(0)$ & 0 & $1(1)$ & 0 & 0 & 0 \\
\hline Anxiety & 0 & 0 & 0 & 0 & $1(1)$ & 0 & 0 & 0 \\
\hline Insomnia & 0 & 0 & $1(0)$ & 0 & 0 & 0 & 0 & 0 \\
\hline Renal and urinary disorders & 0 & 0 & 0 & 0 & $1(0)$ & 0 & $1(0)$ & $1(1)$ \\
\hline Nocturia & 0 & 0 & 0 & 0 & $1(0)$ & 0 & 0 & 0 \\
\hline Polyuria & 0 & 0 & 0 & 0 & 0 & 0 & $1(0)$ & $1(1)$ \\
\hline $\begin{array}{l}\text { Respiratory, thoracic, and } \\
\text { mediastinal disorders }\end{array}$ & $1(1)$ & 0 & 0 & 0 & $2(1)$ & 0 & $1(1)$ & 0 \\
\hline Epistaxis & 0 & 0 & 0 & 0 & $1(0)$ & 0 & 0 & 0 \\
\hline Nasal congestion & $1(1)$ & 0 & 0 & 0 & 0 & 0 & $1(1)$ & 0 \\
\hline Oropharyngeal pain & 0 & 0 & 0 & 0 & $1(1)$ & 0 & 0 & 0 \\
\hline Skin and subcutaneous tissue disorders & $3(1)$ & 0 & 0 & $2(1)$ & 0 & $1(0)$ & $1(0)$ & $2(1)$ \\
\hline Acne & $1(1)$ & 0 & 0 & $1(1)$ & 0 & 0 & 0 & $1(1)$ \\
\hline Aquagenic pruritus & 0 & 0 & 0 & 0 & 0 & $1(0)$ & 0 & 0 \\
\hline Dermatitis contact & 0 & 0 & 0 & 0 & 0 & 0 & $1(0)$ & 0 \\
\hline Dry skin & $1(0)$ & 0 & 0 & 0 & 0 & 0 & 0 & 0 \\
\hline Ecchymosis & $1(0)$ & 0 & 0 & $1(0)$ & 0 & 0 & 0 & 0 \\
\hline Skin irritation & 0 & 0 & 0 & 0 & 0 & 0 & 0 & $1(0)$ \\
\hline
\end{tabular}

Subjects were counted only once per treatment in each row. The table includes all data collected since the first dose of study drug $A E$ adverse event, $B I D$ twice daily, $I R$ immediate-release, $M A D$ multiple ascending doses, MR modified-release, $Q D$ once daily, $Q I D$ four times per day, $T E A E$ treatment-emergent $A E, T I D$ three times per day

${ }^{\mathrm{a}}$ Represents placebo groups (IR placebo and MR placebo) in all cohorts

$\geq 250 \mathrm{mg}$ BID and in the MR $300 \mathrm{mg}$ QD dose group (Fig. 4). On day 14, reductions from baseline in hsCRP of approximately $60-70 \%$ (geometric mean percentage) were seen in the highest dose groups.

\section{Discussion}

These phase 1 studies evaluated the safety, tolerability, PK, and PD of SAD and MAD of IR and MR formulations of PF-06650833, an IRAK4 inhibitor, in healthy adult subjects. PF-06650833 has a favorable safety profile and was well tolerated in single oral doses of IR formulations up to $6000 \mathrm{mg}$ (with food [high-fat meal]) and oral MR formulations up to $300 \mathrm{mg}$, and in multiple oral IR doses up to $1000 \mathrm{mg}$ QID and MR doses up to $300 \mathrm{mg}$ QD (all with standard meal), with no dose-limiting adverse effects identified.

In both studies, the most common treatment-related TEAEs included headache, gastrointestinal disorders, and acne; there were no clinically significant changes in laboratory test results or vital sign parameters at any dose.

In the SAD study, the frequency of TEAEs was slightly more common with PF-06650833 IR doses $\geq 1000 \mathrm{mg}$.
In the MAD study, the highest number of TEAEs occurred in the IR $750 \mathrm{mg}$ BID dose group (the second highest dose tested). TEAEs in both studies were all mild to moderate in severity, and most resolved without intervention. One subject in the IR $1000 \mathrm{mg}$ QID dose group of study 2 was discontinued prematurely for neutropenia having met a protocol-defined ANC threshold for discontinuation. The subject had borderline low ANC at baseline and was asymptomatic. Review of historical laboratory findings for this subject suggested that the subject may have had previously undiagnosed cyclic benign ethnic neutropenia, which could have accounted for the observed fluctuation in ANC, although a causal relationship to PF-06650833 cannot be formally excluded. There were no dose reductions/temporary discontinuations due to TEAEs, serious AEs, or deaths reported in either study. Definitive conclusions about the frequency of TEAEs relative to placebo are limited by the small sample size and relative paucity of TEAEs, and clear dose or regimen relationships were not established.

In the MAD study, atypical crystals were detected in the urine of a total of 22 subjects receiving total daily IR 
a) PF-06650833 IR (doses $\leq 100 \mathrm{mg}$ )

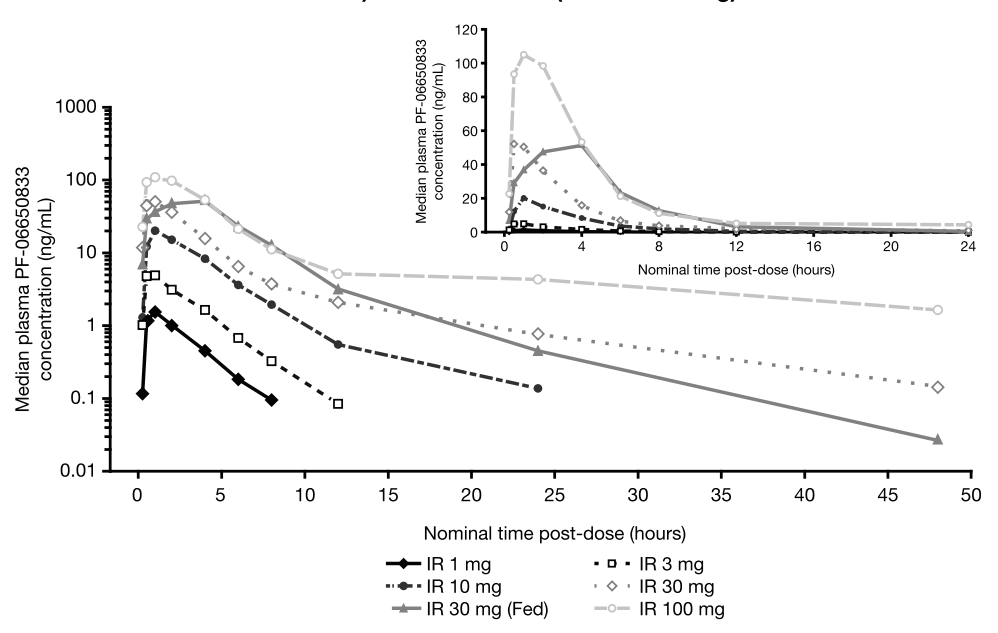

b) PF-06650833 IR (doses $>100 \mathrm{mg}$ )

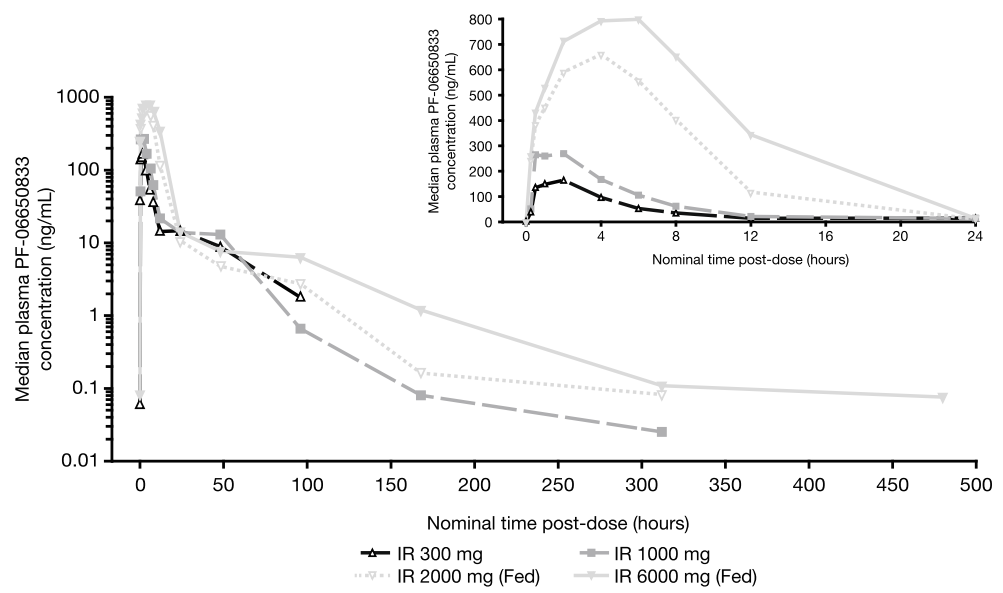

c) PF-06650833 MR (all doses)

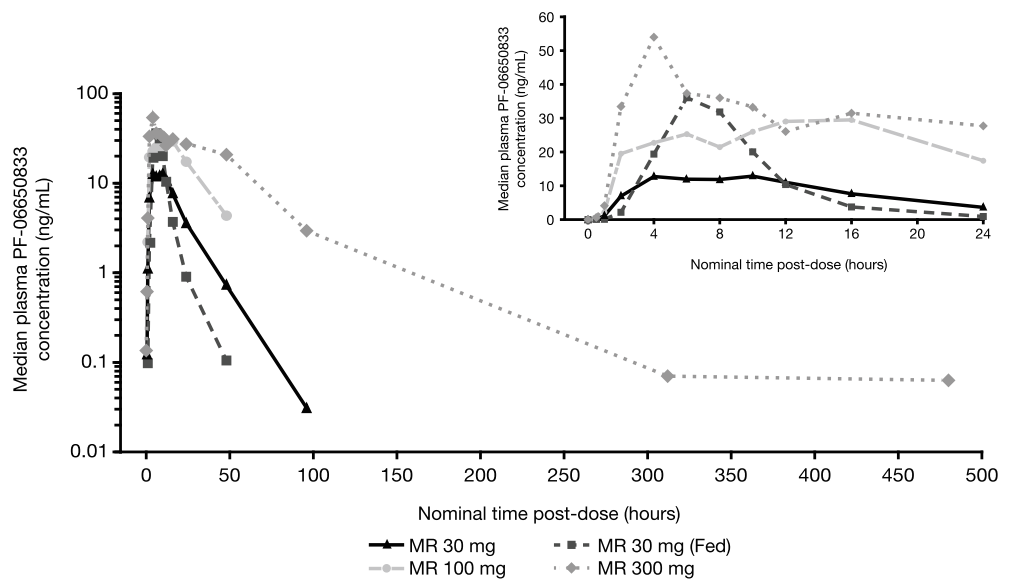

Fig. 2 Median plasma concentration-time profile of SAD of PF-06650833 a IR doses $\leq 100 \mathrm{mg}$, b IR doses $>100 \mathrm{mg}$, and $\mathbf{c}$ MR formulations. All doses were administered orally under fasting conditions (overnight fast of $\geq 10 \mathrm{~h}$ ) unless otherwise indicated. Fed doses were administered after consumption of a high-fat breakfast meal. Summary statistics were calculated by setting concentration values below the LLOQ to 0 . The LLOQ was $0.0500 \mathrm{ng} / \mathrm{mL}$. IR immediate-release; LLOQ lower limit of quantification; MR modified-release; SAD single ascending doses 


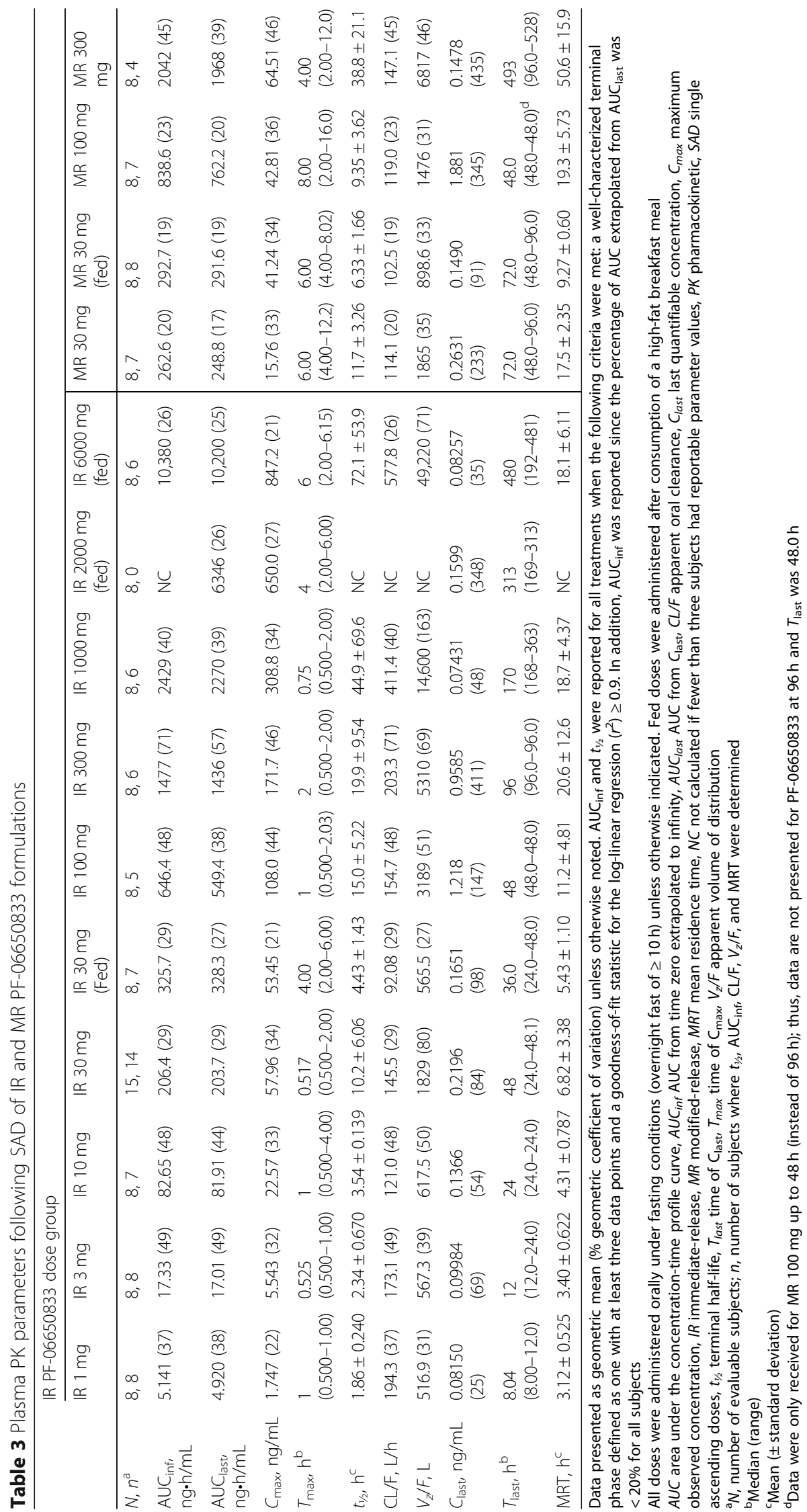




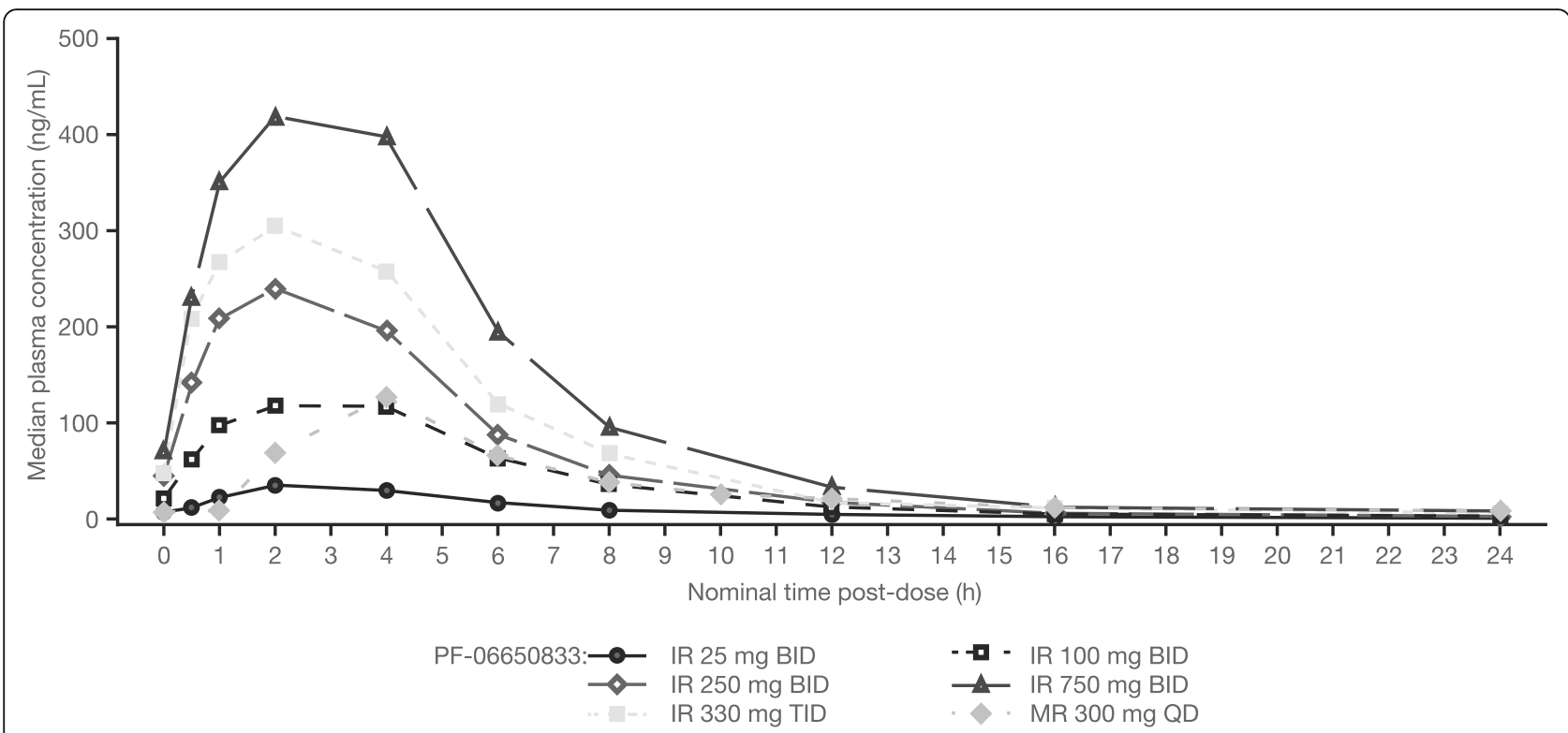

Fig. 3 Median plasma concentration-time profile of MAD of PF-06650833 IR and MR formulations at steady state on day 14. Time post-dose refers to the first morning dose on day 14. Day 14 data for cohort 5 (IR $1000 \mathrm{mg}$ QID) were not available due to premature discontinuation of this cohort on day 9. Summary statistics were calculated by setting concentration values BLQ to 0 . The LLOQ was $0.0500 \mathrm{ng} / \mathrm{mL}$, except four pre-dose samples with $L L O Q$ of $0.100 \mathrm{ng} / \mathrm{mL}$. All doses were administered orally under fed conditions (standard meal). BID twice daily; BLQ below lower limit of quantification; IR immediate-release; LLOQ lower limit of quantification; MAD multiple ascending doses; MR modified-release; QD once daily; QID four times per day; TID three times per day

doses $\geq 330 \mathrm{mg}$ TID or MR $300 \mathrm{mg}$ of PF-06650833 and in 3 subjects receiving placebo. The crystals were found in the urinalyses performed as part of a routine safety laboratory monitoring. The atypical urine crystals were not consistently observed in repeat visits for an individual subject nor was there a pattern observed between subjects at a given dose. Urine crystals at higher abundance $(\geq 15 / \mathrm{hpf})$ were only observed at the highest 2 doses ( $\geq$ IR $750 \mathrm{mg}$ BID), which are in excess of those that are likely to be explored in future clinical trials of PF-06650833. The manifestation of the atypical urine crystals was entirely asymptomatic, was not associated with any clinical or laboratory evidence of adverse effects on the kidney, and was therefore not considered adverse. The etiology of the atypical crystals is currently uncertain but may represent precipitation of parent drug and/ or metabolites in the urine under supersaturated conditions. As the atypical urine crystals were not accompanied by any renal findings, their clinical significance, if any, is unclear, and their occurrence is not an impediment to further clinical development of PF-06650833 for the treatment of autoimmune and inflammatory diseases.

For single oral doses of IR 1-1000 $\mathrm{mg}$ in the fasted state in the SAD study, the increase of PF-06650833 exposure was dose linear over the 1-100 $\mathrm{mg}$ dose range and less than dose linear at higher doses. Consistent with being a high-permeability compound [16], the absorption of PF-06650833 in the fasted state was rapid for the IR formulation, with a median $T_{\max }$ ranging from 0.5 to $2 \mathrm{~h}$ across the dose groups. The apparent half-life of PF-06650833 appeared to increase with dose, with a mean half-life of $1.86 \mathrm{~h}$ at $1 \mathrm{mg}$ and of $44.9 \mathrm{~h}$ at $1000 \mathrm{mg}$, but with large variability. The much shorter half-life observed at lower doses could be due to the serum concentrations of PF-06650833 falling below the quantifiable limit before reaching the terminal elimination phase, which began at approximately $12 \mathrm{~h}$ after dosing. The longer and more variable half-life observed at higher doses could possibly be due to the flip-flop kinetics at the high-dose levels. In addition, multiple peaks were observed in concentration-time profiles of a few subjects after administration of the IR formulation, indicating the possibility of a recycling mechanism, which may also have contributed to a longer terminal elimination phase. PK studies including intravenous dosing would be required to fully delineate the PK of PF-06650833.

MR formulations were developed in order to decrease the dosing frequency and lower the peak-to-trough ratio in future trials. The safety and tolerability of these MR formulations were evaluated in both SAD and MAD studies. Consistent with the general properties of MR formulations, the MR formulation demonstrated delayed $T_{\max }$ and tapered $C_{\max }$ in fasted states. For example, at $30 \mathrm{mg}$, the median $T_{\max }$ was $0.5 \mathrm{~h}$ and $C_{\max }$ was $58 \mathrm{ng} / \mathrm{mL}$ for the IR formulation, while median $T_{\max }$ was $6 \mathrm{~h}$ and $C_{\max }$ was $15.8 \mathrm{ng} / \mathrm{mL}$ with the MR formulation at the 
Table 4 Plasma and urine PK parameters following MAD of IR and MR PF-06650833

\begin{tabular}{|c|c|c|c|c|c|c|c|}
\hline & \multicolumn{7}{|c|}{ PF-06650833 dose group } \\
\hline & IR $25 \mathrm{mg} \mathrm{BID}$ & IR $100 \mathrm{mg} \mathrm{BID}$ & IR 250 mg BID & IR 750 mg BID & IR $1000 \mathrm{mg} \mathrm{QIDa}$ & IR 330 mg TID & MR $300 \mathrm{mg}$ QD \\
\hline \multicolumn{8}{|l|}{ Day 1} \\
\hline$N$ & 8 & 8 & 8 & 8 & 8 & 8 & 8 \\
\hline$A \cup C_{\text {tau, }}, \mathrm{ng} \cdot h / \mathrm{mL}$ & $163.7(26)$ & $566.3(32)$ & $1348(40)$ & $2581(28)$ & $2008(25)$ & $1500(38)$ & $1150(62)$ \\
\hline$C_{\max }, \mathrm{ng} / \mathrm{mL}$ & $29.96(34)$ & $101.8(38)$ & $226.4(35)$ & $470.3(24)$ & $517.3(30)$ & $309.0(37)$ & $149.3(51)$ \\
\hline$T_{\max }, \mathrm{h}^{\mathrm{b}}$ & $2.03(1.00-4.00)$ & $2.03(1.00-4.00)$ & $4.00(2.00-4.00)$ & $3.12(2.03-4.07)$ & $4.00(2.00-4.02)$ & $2.03(2.00-4.00)$ & $4.00(2.00-10.0)$ \\
\hline \multicolumn{8}{|l|}{ Day 14} \\
\hline$N$ & 8 & 8 & 8 & 7 & - & 8 & 7 \\
\hline$A \cup C_{\text {tau, }}, \mathrm{ng} \cdot h / \mathrm{mL}$ & $204.2(26)$ & 776.5 (16) & $1360(39)$ & $2475(24)$ & - & $1599(28)$ & $975.4(65)$ \\
\hline$C_{\max }, \mathrm{ng} / \mathrm{mL}$ & $36.19(31)$ & $127.6(16)$ & $238.5(33)$ & $420.7(25)$ & - & $317.9(27)$ & $146.8(49)$ \\
\hline$T_{\max }, h^{b}$ & $2.00(0.500-4.00)$ & $2.02(1.00-4.00)$ & $2.02(2.00-4.03)$ & $2.00(2.00-4.00)$ & - & $2.00(1.00-4.00)$ & $4.00(2.00-7.50)$ \\
\hline $\mathrm{CL} / \mathrm{F}, \mathrm{L} / \mathrm{h}$ & $122.4(26)$ & $128.9(16)$ & $183.7(39)$ & $302.9(24)$ & - & $206.1(28)$ & $308.0(65)$ \\
\hline$V_{z} / F, L$ & 9650 (37) & 8064 (27) & $10,170(44)$ & $13,160(29)$ & - & $10,070(24)$ & $11,600(46)$ \\
\hline$C_{\min }, \mathrm{ng} / \mathrm{mL}$ & $4.064(46)$ & $14.13(40)$ & 20.07 (76) & $33.07(50)$ & - & $51.48(68)$ & $6.471(55)$ \\
\hline$C_{a v}, n g / m L$ & $17.03(26)$ & $64.72(16)$ & 113.3 (39) & $206.3(24)$ & - & $200.1(28)$ & $40.62(65)$ \\
\hline PTF & $1.868(21)$ & $1.740(16)$ & $1.911(14)$ & $1.868(12)$ & - & 1.307 (18) & 3.383 (37) \\
\hline$R_{\mathrm{ac}}$ & $1.250(19)$ & $1.373(23)$ & 1.009 (13) & $0.9377(32)$ & - & $1.068(26)$ & $0.8985(24)$ \\
\hline$R_{\mathrm{ac}, \mathrm{C} \max }$ & $1.209(22)$ & $1.253(28)$ & $1.052(22)$ & $0.8689(38)$ & - & $1.029(28)$ & $1.078(29)$ \\
\hline$t_{1 / 21}, h^{c}$ & $N R$ & NR & $N R$ & $29.4^{d} \pm 1.78$ & - & $31.4^{\mathrm{e}} \pm 5.60$ & $25.4^{f} \pm 6.41$ \\
\hline MRT, h & NR & NR & $N R$ & $6.15^{d} \pm 0.366$ & - & $5.29^{\mathrm{e}} \pm 1.18$ & $20.3^{f} \pm 9.46$ \\
\hline$A_{e 24} \%$ & $0.7288(27)$ & $0.9414(29)$ & $0.4822(53)$ & $0.4885(24)$ & - & $0.6372(34)$ & $0.300(70)$ \\
\hline $\mathrm{CL}_{\mathrm{r}}, \mathrm{mL} / \mathrm{min}$ & $13.62(19)$ & 18.54 (19) & $13.92(18)$ & 23.14 (19) & - & $18.83(21)$ & 15.39 (30) \\
\hline
\end{tabular}

Data presented as geometric mean (\% geometric coefficient of variation) unless otherwise noted

All doses were administered orally under fed conditions (standard meal)

$A_{e 24}$ cumulative amount of drug recovered unchanged in urine up to $24 \mathrm{~h}$; $A U C$ area under the concentration-time profile curve; $A U C_{\text {tau }}$ AUC from time 0 to time tau, the dosing interval, where tau $=6,8,12$, and $24 \mathrm{~h}$ for QID, TID, BID, and QD dosing, respectively; $B I D$ twice daily; $C_{a v}$ average concentration for the dosing interval; $C L / F$ apparent oral clearance; $C L_{r}$ renal clearance; $C_{\text {max }}$ maximum observed concentration; $C_{\text {min }}$ lowest concentration observed during the dosing interval; IR immediate-release; MAD multiple ascending doses; MR modified-release; MRT mean residence time; NR not recorded; PK pharmacokinetic; PTF peak-trough fluctuation; $Q D$ once daily; $Q I D$ four times per day; $R_{a c}$ observed accumulation ratio; $t_{1 / 2}$ terminal half-life; $T I D$ three times per day; $T_{m a x}$ time of $C_{\text {max }} V_{z} / F$ apparent volume of distribution

${ }^{\mathrm{a}}$ Day 14 data for cohort 5 (PF-06650833 IR $1000 \mathrm{mg}$ QID) were not available due to discontinuation of this cohort on day 9

${ }^{\mathrm{b}}$ Median (range)

cMean ( \pm standard deviation)

${ }^{\mathrm{d}} N=4$

${ }^{\mathrm{e}} N=3$

${ }^{\mathrm{f}} N=6$

same dose. In the fasted state, $\mathrm{AUC}_{\mathrm{inf}}$ of the $\mathrm{MR}$ formulation was also slightly higher compared with the IR formulation at an equivalent dose. In general, in the fasted state, the MR formulation displayed relatively flat concentration-time profiles during the long absorption phase. Overall, the MR formulation exhibited PK characteristics in the fasted state suitable for QD dosing.

Single dose administration of IR formulations of PF-06650833 with a high-fat meal delayed oral absorption of the PF-06650833 IR $30 \mathrm{mg}$ formulation (median $T_{\max }$ of 0.5 and $4 \mathrm{~h}$ under fasted and fed states, respectively) and increased total exposure by $33 \%$ without affecting the $C_{\max }$. In contrast, high-fat meal intake did not delay the absorption of the MR $30 \mathrm{mg}$ dose (median $T_{\max }$ of $6 \mathrm{~h}$ in both fasted and fed states), increased $C_{\max }$ by more than twofold, and decreased $t_{1 / 2}$ by twofold. The shift in $T_{\max }$ and the increase in AUC for the IR formulation in the fed state could be due to an increase in gastric residence time and possible absorption from the upper part of the gastrointestinal tract, whereas the absorption of the MR formulation may be occurring predominantly in the lower part of the gastrointestinal tract.

In the MAD study, on day 1 , following single doses of IR 25 to $1000 \mathrm{mg}$ and MR $300 \mathrm{mg}$, the standard meal led to a slightly more modest delay of absorption compared with the high-fat meal in the SAD study. For example, the median $T_{\max }$ of IR $25 \mathrm{mg}$ under standard meal conditions was $2 \mathrm{~h}$, while the median $T_{\max }$ of IR $30 \mathrm{mg}$ in the SAD study was 0.5 and $4 \mathrm{~h}$ under fasted and highfat meal states, respectively. The MR formulation 


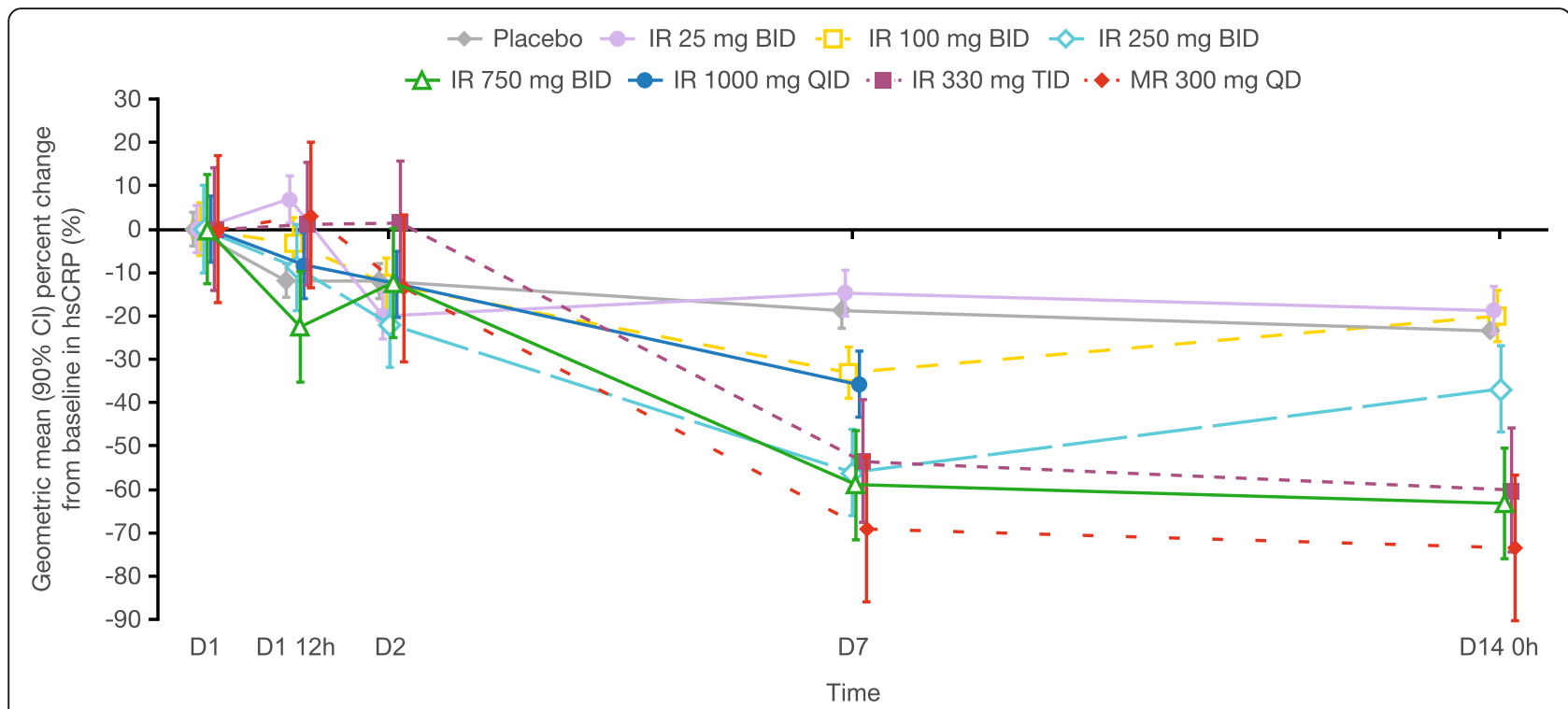

Fig. 4 Geometric mean $(90 \% \mathrm{Cl}$ ) change from baseline in serum hsCRP following MAD of IR and MR PF-06650833 formulations. Baseline was defined as the last pre-dose measurement taken on day 1. Time post-dose refers to the first morning dose. Values below the LLOQ were set to half of the LLOQ in the calculation. The LLOQ of hSCRP was $0.015 \mathrm{mg} / \mathrm{dL}$. Unplanned readings and early withdrawal readings are excluded. The dosing in $1000 \mathrm{mg}$ QID dose group was stopped by the sponsor after the second dose on day 9, and the subjects had their follow-up visits 2 days (approximately $43 \mathrm{~h}$ ) and 13 days (approximately $310 \mathrm{~h}$ ) after the last dose on day 9. BID twice daily; $C /$ confidence interval; $D$ day; $h$ hour; hsCRP high-sensitivity C-reactive protein; IR immediate-release; LLOQ lower limit of quantification; MAD multiple ascending doses

maintained a long absorption phase, with a median $T_{\max }$ of $4 \mathrm{~h}$ and individual $T_{\max }$ ranging from 2 to $10 \mathrm{~h}$ for the MR $300 \mathrm{mg}$ dose under standard meal conditions. At lower doses, half-lives were not reportable either due to $r^{2}<0.9$ or the proportion of extrapolation of AUC being higher than $20 \%$. The half-life for $1000 \mathrm{mg}$ QID was not determined, because the cohort was not dosed beyond day 10 and plasma samples were not collected. The $t_{1 / 2}$ of PF-06650833 at steady state ranged between 25 and $31 \mathrm{~h}$ for the dose groups with reportable half-lives. The accumulation of PF-06650833 for the various dose groups was low, and steady state was reached by day 4 for all dose groups based on the evaluation of $C_{\min }$.

There was a sustained decrease from baseline in serum hsCRP from day 7 to day 14 following administration of multiple PF-06650833 IR formulations with a total daily dose of $\geq 250 \mathrm{mg}$ BID and in the MR $300 \mathrm{mg}$ QD dose group. Since hsCRP is a general marker of inflammation, and specifically a marker of disease activity in RA and other inflammatory diseases, seeing an effect in healthy subjects is encouraging and consistent with PF-06650833 having a pharmacologic effect downstream in the TLR signaling cascade (and likely upstream of IL-6). In concert with prior in vitro and in vivo studies [16-18] and available preclinical data [16], these results suggest that PF-06650833 may have clinically relevant anti-inflammatory effects, supporting its development for the treatment of autoimmune diseases.

\section{Conclusions}

PF-06650833, the first IRAK4 inhibitor to enter human clinical trials, was shown to have a favorable safety profile and be well tolerated in healthy adult subjects up to a single dose of IR $6000 \mathrm{mg}$ (with food [high-fat meal]) and multiple doses up to IR $1000 \mathrm{mg}$ QID and MR 300 mg QD (with food [standard meal]), with no doselimiting adverse effects observed. PK data demonstrated generally anticipated effects on exposure with increasing dose and the effect of food, for both IR and MR formulations. The MR formulation provided sustained exposures that have the potential to allow QD dosing. The accumulated data support continued evaluation in human clinical trials for the treatment of rheumatic and other autoimmune diseases.

\section{Supplementary information}

Supplementary information accompanies this paper at https://doi.org/10. 1186/s13075-019-2008-6.

Additional file 1: Supplemental Methods. Randomization. Blood and urine collection for PKJPD analyses. Blood and urine collection for analysis of safety laboratory parameters. Analysis of vital signs. Figure S1. Dosenormalized a) $C_{\max }$ and b) $A \cup C_{\text {inf }}$ following SAD of IR and MR PF-06650833 formulations. Figure S2. Dose-normalized a) $C_{\max }$ and b) $A U C_{\text {tau }}$ (day 14) following MAD of IR and MR PF-06650833 formulations.

\section{Abbreviations}

AE: Adverse event; $A_{\text {e24: }}$ : Cumulative amount of drug recovered unchanged in urine up to $24 \mathrm{~h}$; ANC: Absolute neutrophil count; AUC: Area under the 
concentration-time profile curve; $A \cup C_{\text {inf: }}$ AUC from time zero extrapolated to infinity; $A \cup C_{\text {last }}: A \cup C$ from $C_{\text {last }}: A \cup C_{\text {tau }}$ : $A \cup C$ from time 0 to time tau, the dosing interval, where tau $=6,8,12$, and $24 \mathrm{~h}$ for QID, TID, BID, and QD dosing, respectively; BID: Twice daily; BLQ: Below lower limit of quantification; BMI: Body mass index; $C_{a v}$ : Average concentration for the dosing interval; Cl: Confidence interval; CL/F: Apparent oral clearance; $C_{\text {last }}$ : Last quantifiable concentration; $C_{r}$ : Renal clearance; $C_{\text {max }}$ : Maximum observed concentration; $C_{\text {min }}$ : Lowest concentration observed during the dosing interval; CYP3A: Cytochrome P450 3A; CYP3A4: Cytochrome P450 3A4; Dn: Dose-normalized; ECG: Electrocardiogram; hpf: High power field; hsCRP: High-sensitivity C-reactive protein; IL: Interleukin; IR: Immediaterelease; IRAK4: Interleukin-1 receptor-associated kinase 4; LC-MS: Liquid chromatography tandem mass spectrometric methods; LLOQ: Lower limit of quantification; MAD: Multiple ascending dose; MR: Modified-release; MRT: Mean residence time; MTD: Maximum tolerated dose; NC: Not calculated; NOAEL: No observable adverse effect level; NR: Not recorded; PD: Pharmacodynamics; PK: Pharmacokinetic; PTF: Peak-trough fluctuation; QD: Once daily; QID: Four times per day; RA: Rheumatoid arthritis; $R_{\text {ac: }}$ : Observed accumulation ratio; SAD: Single ascending dose; SD: Standard deviation; SLE: Systemic lupus erythematosus; $t_{1 / 2}$ : Terminal half-life; TEAE: Treatment-emergent adverse event; TID: Three times per day; TK: Toxicokinetic limit; $T_{\text {last }}$ : Time of $C_{\text {last; }}$ TLR: Toll-like receptor; $T_{\text {max }}$ : Time of $C_{\text {max }} ; V_{z} / F$ : Apparent volume of distribution

\section{Acknowledgements}

This study was sponsored by Pfizer Inc. Medical writing support, under the guidance of the authors, was provided by Jennifer Stewart, PhD, MBA, at CMC Connect, a division of McCann Health Medical Communications, Inc., Radnor, PA, USA, and was funded by Pfizer Inc., New York, NY, USA, in accordance with Good Publication Practice (GPP3) Guidelines (Ann Intern Med 2015;163:461-464).

\section{Authors' contributions}

SID, RSPS, CL, SAG, ZM, and IK were involved in the conception and design of the study and analyses. RSPS, CL, and SAG performed the data and statistical analyses. SID and NS were involved in the subject recruitment, study monitoring, and/or data acquisition. All authors were involved in the data interpretation and manuscript drafting, reviewing, and development. The views and opinions expressed within this manuscript are those of all authors and do not necessarily represent those of the sponsor. All authors read and approved the final manuscript.

\section{Funding}

This study was sponsored by Pfizer Inc.

\section{Availability of data and materials}

Upon request, and subject to certain criteria, conditions, and exceptions (see https://www.pfizer.com/science/clinical-trials/trial-data-and-results for more information), Pfizer will provide access to individual de-identified participant data from Pfizer-sponsored global interventional clinical studies conducted for medicines, vaccines, and medical devices (1) for indications that have been approved in the USA and/or EU or (2) in programs that have been terminated (i.e., development for all indications has been discontinued). Pfizer will also consider requests for the protocol, data dictionary, and statistical analysis plan. Data may be requested from Pfizer trials 24 months after study completion. The de-identified participant data will be made available to researchers whose proposals meet the research criteria and other conditions and, for which an exception does not apply, via a secure portal. To gain access, data requestors must enter into a data access agreement with Pfizer.

\section{Ethics approval and consent to participate}

These studies were conducted in accordance with the International Ethical Guidelines for Biomedical Research Involving Human Subjects, the Declaration of Helsinki, and the Good Clinical Practice Guidelines, along with applicable local regulatory requirements and laws. The study protocols were approved by the Institutional Review Boards and/or Independent Ethics Committee at each study center. All subjects provided written, informed consent.

\section{Consent for publication}

Not applicable.

\section{Competing interests}

All authors are current or past employees of Pfizer Inc. and hold shares in Pfizer Inc.

Received: 7 March 2019 Accepted: 23 September 2019

Published online: 05 December 2019

\section{References}

1. Cross M, Smith E, Hoy D, Carmona L, Wolfe F, Vos T, et al. The global burden of rheumatoid arthritis: estimates from the global burden of disease 2010 study. Ann Rheum Dis. 2014;73:1316-22.

2. Smith E, Hoy DG, Cross M, Vos T, Naghavi M, Buchbinder R, et al. The global burden of other musculoskeletal disorders: estimates from the Global Burden of Disease 2010 study. Ann Rheum Dis. 2014;73:1462-9.

3. Franklyn K, Hoi A, Nikpour M, Morand EF. The need to define treatment goals for systemic lupus erythematosus. Nat Rev Rheumatol. 2014;10:567-71.

4. Rees F, Doherty M, Grainge MJ, Lanyon P, Zhang W. The worldwide incidence and prevalence of systemic lupus erythematosus: a systematic review of epidemiological studies. Rheumatology. 2017;56:1945-61.

5. Smolen JS, Breedveld FC, Burmester GR, Bykerk V, Dougados M, Emery P, et al. Treating rheumatoid arthritis to target: 2014 update of the recommendations of an international task force. Ann Rheum Dis. 2016;75:3-15.

6. van Vollenhoven RF, Mosca M, Bertsias G, Isenberg D, Kuhn A, Lerstrøm K, et al. Treat-to-target in systemic lupus erythematosus: recommendations from an international task force. Ann Rheum Dis. 2014;73:958-67.

7. Sokka T, Hetland ML, Mäkinen H, Kautiainen H, Hørslev-Petersen K, Luukkainen RK, et al. Remission and rheumatoid arthritis: data on patients receiving usual care in twenty-four countries. Arthritis Rheum. 2008;58:2642-51.

8. Khan NA, Sokka T. American College of Rheumatology/European League Against Rheumatism remission criteria achievement in rheumatoid arthritis: data from 32 countries. In: 2011 ACR/ARHP Annual Scientific Meeting Chicago, IL, USA, November 8, 2011. vol. 2462; 2011.

9. Taylor PC, Moore A, Vasilescu R, Alvir J, Tarallo M. A structured literature review of the burden of illness and unmet needs in patients with rheumatoid arthritis: a current perspective. Rheumatol Int. 2016;36:685-95.

10. Kawai T, Akira S. TLR signaling. Cell Death Differ. 2006;13:816-25.

11. Maglione PJ, Simchoni N, Black S, Radigan L, Overbey JR, Bagiella E, et al. IRAK-4 and MyD88 deficiencies impair lgM responses against T-independent bacterial antigens. Blood. 2014;124:3561-71.

12. Sokolove J, Zhao X, Chandra PE, Robinson WH. Immune complexes containing citrullinated fibrinogen costimulate macrophages via Toll-like receptor 4 and Fcgamma receptor. Arthritis Rheum. 2011;63:53-62.

13. Sakkas LI, Bogdanos DP, Katsiari C, Platsoucas CD. Anti-citrullinated peptides as autoantigens in rheumatoid arthritis-relevance to treatment. Autoimmun Rev. 2014;13:1114-20.

14. Kono DH, Haraldsson MK, Lawson BR, Pollard KM, Koh YT, Du X, et al. Endosomal TLR signaling is required for anti-nucleic acid and rheumatoid factor autoantibodies in lupus. Proc Natl Acad Sci U S A. 2009;106:12061-6.

15. Guiducci C, Gong M, Xu Z, Gill M, Chaussabel D, Meeker T, et al. TLR recognition of self nucleic acids hampers glucocorticoid activity in lupus. Nature. 2010;465:937-41.

16. Lee $\mathrm{KL}$, Ambler CM, Anderson DR, Boscoe BP, Bree AG, Brodfuehrer Il, et al. Discovery of clinical candidate 1 -\{[(2S,3S,4S)-3-Ethyl-4-fluoro-5-oxopyrrolidin2-yl]methoxy\}-7-methoxyisoquinoli ne-6-carboxamide (PF-06650833), a potent, selective inhibitor of Interleukin-1 receptor associated kinase 4 (IRAK4), by fragment-based drug design. J Med Chem. 2017;60:5521-42.

17. Kelly PN, Romero DL, Yang Y, Shaffer AL 3rd, Chaudhary D, Robinson S, et al. Selective interleukin-1 receptor-associated kinase 4 inhibitors for the treatment of autoimmune disorders and lymphoid malignancy. J Exp Med. 2015;212:2189-201.

18. Tumey LN, Boschelli DH, Bhagirath N, Shim J, Murphy EA, Goodwin D, et al. Identification and optimization of indolo[2,3-c]quinoline inhibitors of IRAK4. Bioorg Med Chem Lett. 2014;24:2066-72.

19. McElroy WT, Tan Z, Ho G, Paliwal S, Li G, Seganish WM, et al. Potent and selective amidopyrazole inhibitors of IRAK4 that are efficacious in a rodent model of inflammation. ACS Med Chem Lett. 2015;6:677-82.

20. Cushing L, Winkler A, Jelinsky SA, Lee K, Korver W, Hawtin R, et al. IRAK4 kinase activity controls Toll-like receptor-induced inflammation through the 
transcription factor IRF5 in primary human monocytes. J Biol Chem. 2017; 292:18689-98.

21. Diczfalusy U, Nylén H, Elander P, Bertilsson L. 43-Hydroxycholesterol, an endogenous marker of CYP3A4/5 activity in humans. Br J Clin Pharmacol. 2011;71:183-9.

\section{Publisher's Note}

Springer Nature remains neutral with regard to jurisdictional claims in published maps and institutional affiliations.

Ready to submit your research? Choose BMC and benefit from:

- fast, convenient online submission

- thorough peer review by experienced researchers in your field

- rapid publication on acceptance

- support for research data, including large and complex data types

- gold Open Access which fosters wider collaboration and increased citations

- maximum visibility for your research: over $100 \mathrm{M}$ website views per year

At BMC, research is always in progress. 